Tipping as a Tool for Gendered Exploitation in Restaurants: An Analysis on the Impacts of the Employment Standards Act for Women Serving in Ontario

\author{
by \\ Lydia M. Dobson
}

A thesis submitted to the Faculty of Graduate and Postdoctoral Affairs in partial fulfillment of the requirements for the degree of

Master of Arts

in

Sociology

Carleton University

Ottawa, Ontario

(C) 2014, Lydia M. Dobson 


\begin{abstract}
Contemporary Canadian labour markets are marked by increasingly precarious and unstable working conditions, predominantly found in the secondary labour market (Thomas, 2009). Research indicates that women have and continue to be overrepresented in professions market by part-time and low-waged work in this market (Vosko, 2006). Following trends in the gendered segmentation of labour is legislation that acts to facilitate differential standards of employment for women. This thesis investigates the Ontario Employment Standards Act (ESA), with respect to its influence on waitresses in Ontario. Interviewing women occupying serving positions about tipping procedures and workplace standards, I argue that gaps in the ESA around protections over tips facilitate industry-wide standards in restaurants that systemically subordinate and exploit women workers in the food and alcohol service sector.
\end{abstract}




\section{Acknowledgements}

I would like to express my sincerest gratitude to my thesis supervisor, Professor Neil Gerlach, for providing an excellent foundation of knowledge and for all of his support and encouragement throughout the writing process.

I would also like to thank my second reader, Professor Adrian Smith, particularly for his role in introducing me to a body of research that is both integral to my thesis and has largely shaped my academic endeavours going forward.

I am grateful to Professor Aaron Doyle for his support and guidance throughout my graduate school experience at Carleton University.

I am incredibly thankful to my friend and mentor Yavar Hameed for inspiring me to take on this research and being so supportive throughout.

I am very appreciative to all of the participants in this study for donating their time and experiences to my research.

Finally, I am grateful to my friends and family for all of their support and motivation. 


\section{Table of Contents}

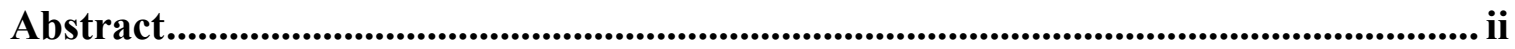

Acknowledgements ...........................................................................................................ii

Table of Contents .............................................................................................................

List of Tables .......................................................................................................................... vii

List of Appendices...................................................................................................................... viii

1 Chapter: Introduction ........................................................................................................ 1



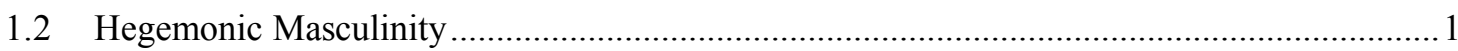

1.3 Gendered Working Relationships and Restaurants .........................................................

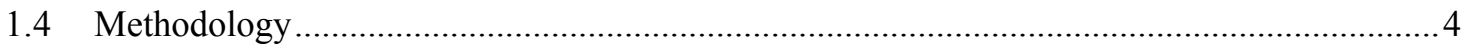

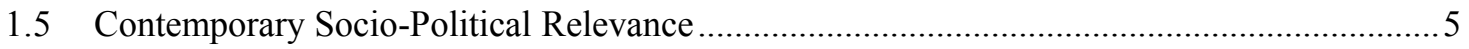

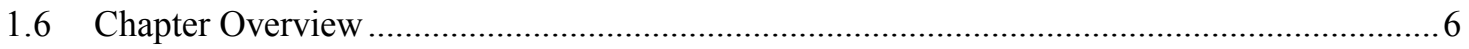

2 Chapter: Theory and Methodology ................................................................................. 8

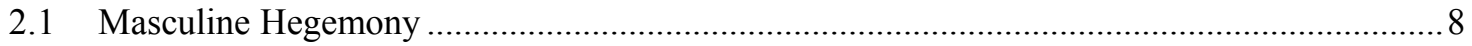

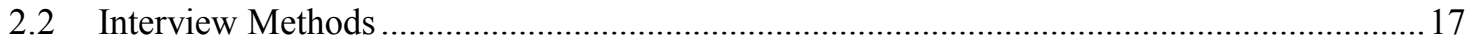

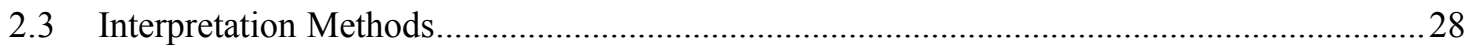



3 Chapter: Gendered and Precarious Employment ....................................................... 33

3.1 Historical Context of Gendered Labour Segmentation ......................................................... 33

3.2 Contemporary Employment Standards in Ontario ......................................................... 42

3.3 Literature around tipping and sexualization in the restaurant industry ................................55

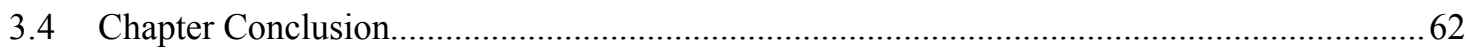

4 Chapter: Data .............................................................................................................. 64 


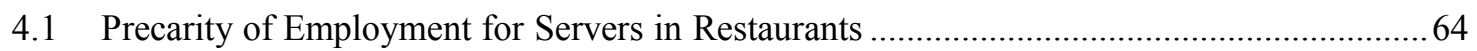

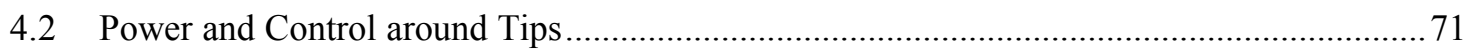

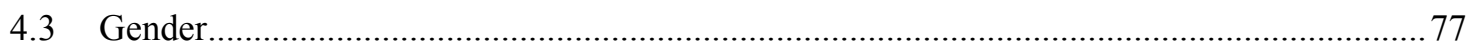

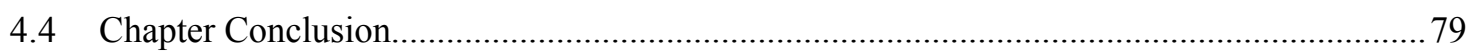

5 Chapter: Interpretation of Data .................................................................. 80

5.1 Restaurants within broader Gendered Employment Trends of Precarity............................... 80

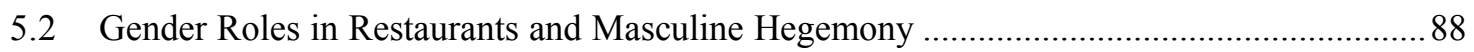

5.3 Legislative Problems and Solutions around Contemporary Tipping Practices .................... 95

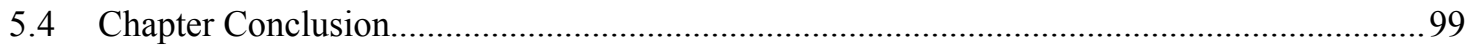

6 Chapter: Conclusion .............................................................................................. 101

Appendices....................................................................................................................... 104

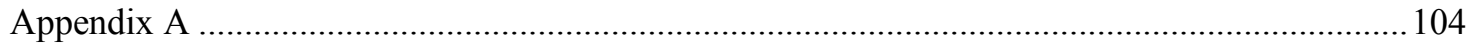

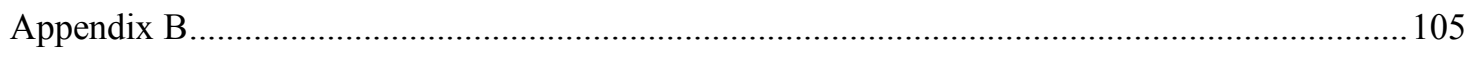

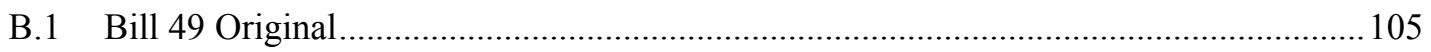

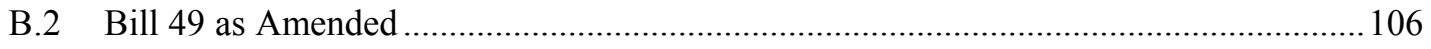

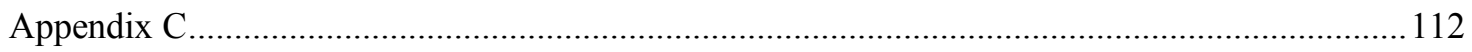

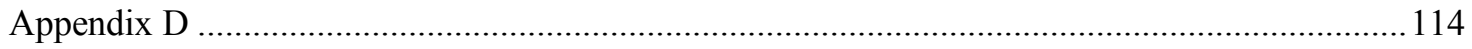

Bibliography ................................................................................................................... 115 


\section{List of Tables}

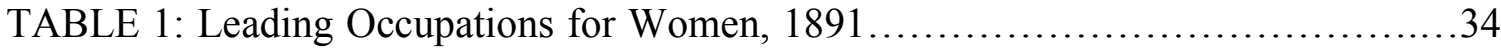

TABLE 2: Leading Occupations for Women, 1921_............................. 35

TABLE 3: Distribution of employment by occupations, 1987, 1999 and 2009.........41

TABLE 4: Stability and Duration of Restaurant Work.......................... 65

TABLE 5: Factors Impacting Tips outside of Servers' Control.....................69

TABLE 6: Results of Questions 3, 4 and 5 (on Gendered Positions in Restaurants)......78 


\title{
List of Appendices
}

\author{
Appendix A.
}

Appendix B.

B.1 Sub-Appendix

B.2 Sub-Appendix

Appendix C .

Appendix D. 


\section{Chapter: Introduction}

\subsection{Introduction}

The main purpose of my master's thesis research is to develop a literary contribution that addresses the intersection of research on precarious work, gender roles in restaurants and Canadian employment legislation by grounding practical experiences of restaurant servers within these fields of study. In my experiences as a waitress and bartender over the last eight years, I have become knowledgeable about the methods of distributing and controlling tips used by managers and owners of restaurants and how they exacerbate exploitative employment relationships. While these vary greatly depending on the establishment, a commonality that perpetuates the existence of such inequities is the inability of serving staff to receive meaningful governmental protection through the Ontario Employment Standards Act (ESA). As such, I ask: How does ESA legislation around gratuities and tipping impact equity in standards of employment for women serving liquor in Ontario? What reforms would adequately resolve exploitative ${ }^{1}$ practices that result from tipping regimes?

\subsection{Hegemonic Masculinity}

I adopt a critical theoretical approach to understanding the relations between workers and employers. That approach acknowledges the dynamics of power and control in these relations employing Gramsci's (1994) concept of hegemony and Connell's (Connell and Messerschmidt, 2005) extension of it to hegemonic masculinity. For

\footnotetext{
${ }^{1}$ Understandings of exploitation in this paper will be explored predominantly through the mechanisms by which tips are used to financially exploit women in serving positions, while also investigating the gendered and sexualized nature of exploitation on restaurants.
} 
Gramsci, hegemony is the process by which group one maintains power over another through coercion and consent (Gramsci, 1994). Connell's research on masculine hegemony in the workplace informs my discussion of the methods that employers engage with to exploit staff through tipping processes and the systemic and gendered nature of such practices (Connell and Messerschmidt, 2005). Here, I conceptualize tipping governance by employers as a practice which is inherently gendered seeking to explore these processes in a comparative analysis with masculine hegemony, illustrating the role of hegemony in reinforcing gendered exploitations in restaurants.

\subsection{Gendered Working Relationships and Restaurants}

Demonstrative of the need to apply a critical Gramscian theoretical lens of hegemonic masculinity to research on gender in restaurants is the large body of inquiry that has been undertaken to analyse gender roles and sexual exploitation within such establishments (Rasmusson, 2011; Lerum, 2004; Hall, 1993; Johnson, 2005; Creighton, 1982; Gilbert, Guerrier and Guy, 1998). Over the past three decades a consistent stream of research has been conducted which analyses the existence and construction of gender roles in restaurants, focusing primarily on sexual representations of women in waitressing positions (Hall, 1993; Lerum, 2004; Johnson, 2005; Rasmusson, 2011). This body of research, however, has not engaged significantly with the theoretical frameworks on masculine hegemony and its perpetuation in restaurants.

In a similar strain of research, efforts have been made to investigate the social relations and managerial implications of tipping procedures in restaurants. This emerging line of inquiry is primarily conducted within the context of business and market research, appearing in journals on hospitality management and service marketing (Lin 
and Namasivayam, 2011; Liu, 2008; Maynard and Mupandawana, 2009; Von Massow and McAdams, 2012). While capable of providing insights towards the complexity of tipping processes and implications for both staff and owners, the audience of this research is predominantly assumed to be industry and market professionals.

In order to address the legal standards around employment and tipping, my thesis will draw upon a body of literature which engages with the intersection of gender, precarious work and Canadian employment and labour laws (Vosko, 2000; Vosko, 2006; Vosko, 2011; Fudge and Vosko, 2001, Thomas, 2009). This research focuses on the legal development and implementation of employment standards in Canada through both quantitative methods involving the development of comprehensive statistics as well as qualitative methods of critical inquiry into the role of gender in employment. In Vosko's extensive work on gender and precarious employment in Canada, she has called for research which grounds the broad claims of her work in qualitative case studies (Vosko, 2006). My research will apply the wide-ranging claims of these studies on employment legislation and gendered precarious work by using the Ontario ESA as an example of legislation and restaurant servers as the gendered precarious workers. This contributes by substantiating the claims of this line of research while also broadening the implications of my thesis.

Overall, my thesis research aims to link inquiry on gendered precarious employment and legislation with the context-specific research that has been conducted on gender roles in restaurants and tipping procedures while applying a critical lens on legislation and working relationships in hopes of bringing about social change. 


\subsection{Methodology}

Following the literature review, I present my findings based on data collected through the interview process. Ten participants were selected who have worked as servers in Ontario for no less than three years. As this research aims to explore the experiences of women, all participants are women. The types of restaurants for which the participants have worked are limited to those that serve liquor, as the legislation being assessed is limited to liquor serving restaurants.

The interview questions were broadly framed and mostly open-ended to allow participants to discuss the topics which they considered to have been most impactful in their working experiences (See Appendix D). For example, servers are asked to recall personal experiences which might exemplify a certain topic in the work place and are probed based on these individualized experiences. This method of interviewing engages with both feminist research methods and participatory action research. Following Hawkseworth and Oakley, I intended to engage with feminist methodology by discarding traditional masculine methods of guiding interviews and distancing myself from participants (Hawkseworth, 2006; Oakley, 1981). Rather, I have used the interview process to create a rapport with the participants and allow for flexibility in the direction that they chose to take the discussion. In giving the participants the discretion to discuss concerns which they deemed important, my interview process was informed by participatory action research which attempts to give increased control to participants in guiding research direction and goals (Packard, 2008; Plush, 2012; Waite and Conn, 2012). 
The primary focuses of the interview questions were on gender roles and tipping structures in Ontario restaurants. Following much of the pre-existing body of literature on women in restaurant work, my interview data is demonstrative of overtly gendered employment relationships and workplace expectations. Through simultaneously investigating restaurant models of gratuity distribution and production, the interview process provides an avenue from which to explore the intersection and reproduction of these complex social relations.

\subsection{Contemporary Socio-Political Relevance}

Since 2010, Ontario's New Democratic Party (NDP) has advocated for a bill to "protect employees'tips" ${ }^{\prime 2}$. Despite the extremely simplistic nature of the Bill, which reads only: "An employer shall not take any portion of an employee's tips or other gratuities.", two attempts to pass the bill through parliament have been defeated. As Bill 114, the prospective legislation succeeded in two readings without contention, however, was laid to rest following the prorogation of parliament. As Bill 49, the Bill received extensive amendments from the Standing Committee, but was not assigned a third reading prior to election and has, again, been laid to rest. While server's associations and workers' rights advocates have supported the legislation through these rounds in parliament, recurring skepticism of the bill questions whether it is extensive enough to substantially decrease the exploitation of serving staff through controls over tips. Through an investigation of the methods by which tip-based exploitation is produced, my thesis examines the

\footnotetext{
${ }^{2}$ These attempts include: Bill-114, An Act to amend the Employment Standards Act, 2000 with respect to tips and other gratuities, $39^{\text {th }}$ Parliament, Ontario, 2010 Bill-49, An Act to amend the Employment Standards Act, 2000 with respect to tips and other gratuities, 40 Parliament, Ontario, 2013
} 
potential efficacy of this legislative reform to prevent both financial and gender based exploitative practices, as well as providing alternate legislative solutions.

\subsection{Chapter Overview}

This thesis is separated into four central chapters. Chapter 2 outlines the methodological approaches applied in accessing and analyzing the data produced. Details around the methods of the interview process and application of theoretical analysis through the lens of masculine hegemony are explained in this section. Chapter 3 is a literature review highlighting the historical context of gendered employment and labour legislation in Canada, providing a foundation from which to explore contemporary standards in Ontario and under the Ontario Employment Standards Act. This chapter begins by exploring the historical context of the gendered segmentation of labour, followed by a detailed analysis of the development and procession of the Ontario Employment Standards Act. Finally, I discuss literature around the gender roles associated with women in the serving industry, allowing for an overview of the established norms in this industry. These norms are used to frame the broader implication of this case study.

Next, chapter 4 proves the data attained through the interview process. This is broken into three sections: employment conditions, tipping (in)equities, and gender roles. Chapter 5 examines the data gathered in the interview process to provide an analysis of several central themes. The precariousness of serving work for women in Ontario is established and placed within the broader themes identified in the literature review around segmentation of labour, employment legislation and gendered roles within restaurants. This contextualization is provided in conjunction with an understanding of 
serving work as it exists within the context of hegemonic masculinity. Once this understanding of serving work, tips and their interrelation, which facilitates continued oppressive norms and precarious labour for women is established, the specific implications of the ESA are assessed. In this section, recommendations for positive and more equitable change are made regarding both industry standards and legislative reforms. The final chapter provides an overview of the central themes and major conclusions to be drawn for this research and situate it in the broader socio-political, sociological and legal disciplines for which it is relevant. 


\section{Chapter: Theory and Methodology}

\subsection{Masculine Hegemony}

In order to meaningfully assess the overarching themes of gendered subordination in Canadian labour legislation and practice, Gramsci's conceptual framework of hegemony and its extension, masculine hegemony, will be applied. The application of such theoretical analysis provides a context from which to understand the broader methods of control exercised through the gendered segmentation of labour, legislation and their resulting continuances on a micro level in restaurants. This theoretical interpretation will also facilitate an approach for effectively investigating methods of resisting male dominance in the contemporary social context of restaurants and in broader ideological understandings of gender roles.

\section{Hegemony}

The concept of hegemony was developed into its current theoretical form by Antonio Gramsci. Rather than perceiving capitalism as a system that would inevitably fall to proletarian revolution, Gramsci saw its proliferation over time and studied the means by which capitalism sustained and increased power and control. A Gramscian analysis of the forces by which the bourgeoisie are able to dominate capitalist society accepts the Marxist analysis of power by force, but elaborates on this to include a more detailed analysis of the means by which the masses consent to their own subordination and exploitation. Based on Marxist concepts of superstructure and structure, Gramsci claims that hegemony is the unity of the two, in which power based on dominance and 
production is rationalized by an ideology incorporating compromise and consensus (Cox, 1977). The consensus given by the working class is facilitated through a confidence in the prestige "which the dominant class enjoys as a result of its position of power in the world of production" (Gramsci, 1994, p. 12). Thus, hegemony is the result of both ideological coercion by the bourgeoisie as well as the juridical legal governance of state powers. In the event that ideological apparatuses of control, such as media, educational institutions and patriarchal social structures are ineffective, resistance to them will be met with forced control.

\section{Masculine Hegemony}

Connell's extension of hegemony to include an analysis of hegemonic masculinity is the study of the ideological powers that sustain patriarchal dominance in contemporary Western culture. Connell describes the concept as revolving around "gender practice which embodies the current legitimacy of $[\ldots]$ the domination of men and the subordination of women.” (Connell, 2005, p. 77). In agreement with Gramsci's conceptualization of hegemony, Connell perceives masculine hegemony as primarily comprised of ideological forces that act to reinforce the hierarchy of men to women. He notes, however, that there do exist in contemporary societies legislative and juridical governing powers that will step in to affirm the legitimacy of certain forms of masculine dominance (Connell, 2005).

Also clearly articulated is the changing nature of masculinities over time and culture. While some ideological characteristics of masculinity have become eroded, its core value of male dominance and the subordination of women remains. An example of this would be the man of the house being the sole breadwinner of the family. In 
contemporary society, it is more likely that women will also be employed yielding a dual income for the household. However, it is still more likely that the woman is employed in more precarious and low paid work than her husband. Thus, women remain subordinate to men and hegemonic masculinity is continued.

Just as hegemonic masculinity refers to the ideological norms and values around masculinity, it must also infiltrate the norms and values of femininity in order to fully reinforce patriarchal standards (Connell, 2005). While state leaders will actively decree the equality of women in modern society, and the masses are quite satisfied to accept this notion, it is clear that the contours of hegemonic controls remain in full effect; they have simply been altered over time. Tables 1 and 3 are strong examples of this continuation. Although women are not employed primarily as servants as they were in 1891, the leading profession nearly a century later, administrative/clerical work, remains subordinate to men in both wages and prestige. Ideologically professions have become entrenched with gendered expectations. A 1901 article on the state of women's work claims that; "Whatever [work] tends to unsex women should be frowned upon by public opinion, and, if necessary, prohibited by law." (Finck, 1901, p. 76). These ideals of femininity in the workplace have transcended through time, yet are now articulated on much different channels and far less overtly. Contemporary society sees the ideological controls around gender roles and work predominantly through media representations and continued social structures. It is therefore, integral to this research on restaurants, that the subordinate segmentation of women in serving positions be analyzed as it exists in a broader cultural understanding of women's subordination in the labour market. Hegemony and the Gendered Segmentation of Labour: 
Important to discuss in this study of masculine hegemony is the patriarchal hegemony that exists in contemporary labour markets as well as the legislation that governs them. The construction of masculinity and femininity acting to distinguish a separation of powerful and subordinated genders discussed above, are only partial to the networks of hegemonic control that act to sustain patriarchal values in labour and legislation. As is discussed in greater detail in the following chapter's review of gendered and segmented work, contemporary Canadian society has a well established divide of work by gender. Predominantly, the employment which has become marked as women's work is that which is lesser paid, less stable and more likely to be part-time (Vosko, 2006). The reasons for the marginalization of women into the secondary and more precarious labour market can be understood in relation to the maintenance of hegemony and capitalist control.

Capitalism in industrial society is premised on the existence of wage labour. For the production of wage labour, however, it is imperative that social reproduction occur, reinforcing the status quo of capitalist values (Cohen, 2013). Social reproduction takes the form of educating and raising children as well as household tasks which have become gendered as feminine. The process by which these actions become feminized can be understood as a part of the hegemonic process towards maintaining control in a capitalist system. Just as it is imperative that the male bread-winner participate in wage labour, it is essential that each new generation is educated to internalize the oppressive social order of capitalism and thus consent to their own subordination to the wage labour process. The process of maintaining hegemonic control is premised on women providing social reproduction of capitalist order (Cohen, 2013). Feminist scholars have attributed 
Gramsci's analysis of hegemony and its ability to encompass the role of social reproduction into an understanding of the maintenance of capitalist order as an important tool for conceptualizations of patriarchal oppression (Ledwith, 2009).

As a result of the need to maintain this relationship women have largely been relegated into the secondary labour market. This labour market can be understood as subordinate to the primary labour market in that it is marked by full time and continuous labour (Thomas, 2005). The social reproduction of gender roles and gendered segmentation of labour, thus, acts to uphold capitalist order while also reifying gendered social reproduction. In order to explicate the hegemonic influence and reasons for sustaining gendered labour segmentation, we must consider the connection of social reproduction to wage labour.

As women have become integrated into wage labour, the social reproduction of consent to subordination within capitalist social order becomes disturbed. For this reason it is integral to hegemonic capitalist order that women are prevented from attaining the full integration into wage labour. Industries marked by part-time, unstable and lowwaged work in the secondary labour market that have become feminized act to uphold the capitalist model of social control which holds paramount the white male breadwinner (Hooks, 2005). A feminist analysis of precarious labour, as discussed in section 3.1, is able to provide a detailed and specific understanding towards the mechanisms by which contemporary Canadian markets develop and sustain the precariousness of women's work. 


\section{Hegemony, Legislation and Rights:}

Hunt describes hegemonic controls as being enacted through two steps. "First, a successful hegemony needs to incorporate values and norms which contribute to maintaining a minimum standard of social life. Second, the process by which, as a result of actual struggle or the apprehension of it, a dominant bloc engages in a more or less self-conscious 'compromise' to incorporate some elements of the interests of a subordinate group." (Hunt, 1990, p. 311). Much as the social reproduction of gendered segmentation in labour can be thought of as the tool used to "incorporate values and norms which contribute to maintaining a minimum standard of social life", employment and labour legislation can be considered the "'compromise' to incorporate some elements of the interests of a subordinate group" (Hunt, 1990, p. 311). Labour and employment legislation provide both the compromise of protections to the subordinate working class, while also legitimizing, through law, their positions as subordinate. Thus, rights based legislation can be thought of as a tool which ultimately reinforces the hegemonic bloc (Hunt, 1990).

A more specific consideration of gender and rights based compromise, enables the analysis of a two-tiered system of control over work. Traditionally, the protections and empowerment of collective bargaining have been afforded to trades that predominantly employ men. As a result male-dominant industries have the ability to become more capable of securing more stable and better-paid working conditions under the malebreadwinner model. In contrast, employment legislation, which provides legislative minimum standards of working conditions has traditionally governed the working relationships of women. As a result, patriarchal norms around women's work have been 
constructed as inferior to male-dominated industries. Thus working relationships for women-dominated industries are more likely to be precarious and unstable.

Considerations around rights based laws and counter-hegemony are able to provide a framework from which to understand the potential outcomes of legislative reform. Counter-hegemony may be successful in efforts that are based in rights based legislation, however, full emancipation is not likely to occur without the alteration of broader social understandings (Hunt, 1990). It is with this in mind, that investigations into to efficacy of the ESA and its proposed reforms will be considered.

Application of Hegemony to Understanding of Restaurants:

The research process in this study involves understandings of masculine hegemony as existing on two interconnected levels. The first, which will be investigated, is in the context of the workplace. Through interviews with restaurant servers, the methods by which women are subordinated by employers and customers will be assessed. This includes an assessment of both the ideological methods by which staff are willing to work in conditions which facilitate their own exploitation and the punitive methods by which employers are able force compliance. The forced compliance which will be under predominant investigation is that which is exercised over tips and gratuities in restaurants. As Von Massow and McAdams have briefly touched on in studies around tipping processes, many servers have experienced situations where tip earning potential was controlled by management and exercised as a punitive measure (Von Massow \& 
McAdams, 2012). The interview-based approach ${ }^{6}$ of this research seeks to explore the prevalence of this punitive measure and its relation to subordination and dissent.

Application of Hegemony to Understanding Gendered Segmentation of Labour and ESA:

Data provided from interviews with women in serving positions will act as the dominant source from which to draw conclusions around the actual working conditions in restaurants. These understandings will, then, be applied more broadly to the macro level of contemporary labour legislation and the segmentation of gender. The ESA will be interpreted as a tool capable of two conflicting outcomes. In one sense, it will be interpreted as one that enforces and facilitates masculine hegemony by allowing for the exploitation of women in serving positions. It will also be understood as a rights based legislation which may be operated as a mechanism for creating positive social change. The specific exemption of tips under the legal definition of wages and the failed attempts to secure adequate protections of gratuities for servers will be assessed with consideration of the ground level effects that this has for women's working conditions. The intersection of this juridical form of control over workplace standards and the ideological norms around women's work and femininity in the workplace will then be interpreted as they relate to masculine hegemony in restaurants and in broader social understandings.

\section{Counter-Hegemony and Resistance:}

Resistance and counter-hegemony will be understood as operating on both the micro-level of Ontario restaurants and on the macro-level of gendered segmentation of labour. In analyzing the interview data and coming to conclusions around what can and should be done in the future to prevent or at least alleviate some of the gendered

\footnotetext{
${ }^{6}$ Section 2.3 will elaborate in great detail the specifics of the interview-based process.
} 
exploitation of women in the restaurant industry, methods of resistance theoretically proposed to counter hegemony will be applied. Gramsci's work largely focuses on the ideological apparatuses that continue the complacency of individuals and groups to subordination and exploitation. Following this line of thought, social change and resistance to the ideological forces, which support capitalism involves troubling and removing these ideas from popular belief and replacing them with a different ideological understanding. Interview results are able to provide an understanding of the mechanisms by which gendered based subordination is produced in restaurants through both consent and coercive tactics. These will be assessed in greater detail to provide meaningful suggestions for servers experiencing gender based subordination and exploitation.

The interconnected nature of poor working conditions for servers to broader regimes of gendered labour segmentation of women into precarious work must also be considered in this analysis. Current employment legislation will be analyzed as a coercive tool, which allows employers to force consent upon servers, while also being capable of providing meaningful rights based protections for servers.

\section{Conclusion:}

This chapter outlines the theoretical framework of hegemonic masculinity and its application to the gender based inequities in workplaces (micro level) as well as the social segmentation of labour industries (macro level). This theoretical structure of understanding will inform analysis on the gendered segmentation of labour in Canada the legislative reinforcement of such controls. Gramsci's notion of hegemony and its extension to masculine hegemony have been outlined with consideration to their application to working relationships in restaurants, followed by a discussion around 
social reproduction and gendered segmentation of labour. Finally, employment standards are positioned as tools that can be used to both oppress and operate in conjunction with efforts towards counter-hegemony. This understanding of employment standards is used in chapter 5 to evaluate the role of the ESA in gender based exploitative practices.

\subsection{Interview Methods}

In order to conduct research consistent with the underlying themes of this study, I have employed feminist methods in the interview process. In this section, the process of conducting interviews will be reviewed as it relates to theoretical values of this study. I will outline the reasons for selecting a feminist interview approach and detail how it was employed. Respondent sample selection details will be provided as well as the methods by which interview questions and modes have been selected. Ethical considerations and protections have also been undertaken which this portion of the paper will explain and provide reasoning for. In order to provide a detailed understanding of both the actual methods and the motivations for them, this section will begin with a practical description of the research methods, followed by an explanation of the selection of such methods and reflection based upon having employed them.

Ten participants have been selected who have worked as servers in Ontario for no less than three years. As this research aims to explore the experiences of women, all participants are women. The types of restaurants for which the participants have worked are limited to those which serve liquor, as the legislation being assessed is limited to liquor serving restaurants. Having personally been employed in Ontario restaurants for several years, respondents have been selected based on my own previous social 
connections. While these vary in closeness, I have known all respondents in some capacity prior to beginning the interview process. Attached as Appendix C is the script, which was used to determine eligibility and select participants. The interview questions were broadly framed and open-ended in order to allow participants to discuss the topics which they considered to have been most impactful in their working experiences. This included fifteen open-ended, structured questions and further probing based on responses given. Attached as Appendix D are the interview questions. Interviews took place between January and May of 2013. Each interview lasted no longer than one hour. Data was recorded by real-time typed transcription.

The application of feminist research methods in the interview process relates to both the purpose of this research as well as the value of such methods to data production. In producing research which aims to reveal gendered inequities in both the workplace and in broader legal frameworks in Canada, it is consistent and integral to apply methods which prevent the potential for power imbalance. The interview process itself may be undertaken through various methods, the validity of which have been contested over time. Traditional interview based methods applied in the social sciences are argued to have been overly masculine and hegemonic in power dynamics between the researcher and respondent. These interview methods involve avoiding conversation with respondents and engaging in a one way dynamic of question and answer, while adhering to a certain degree of detachment from the respondent (Oakley, 1981). Feminist interviewing involves undertaking to prevent this sort of hierarchal relation between interviewer and respondent. Further, conversation is welcomed and acts as a tool from which to attain good rapport and welcomes more personal details into the process 
(Oakley, 1981). However, there is some varying academic debate surrounding the degree to which an interviewer should become amicably involved with respondents, as it may skew results and cause the effect of responses which seek to appeal to the interviewer (Oakley, 1981; Cotterill, 1992). This concern is a possibility in any interview-based research. For example, an overly reserved and cold process may yield results that have been skewed by the participants' desire for approval. Further, researchers have described the interview process as one which fluidly transfers power from researcher to respondent (Cotterill, 1992), noting that the power lies predominantly with the researcher to navigate this control. Advocates of feminist interview models have articulated that absolute perfect methods are not practically attainable (Oakley, 1981). As a result, I have adopted methods with consideration to my particular research, which follow the broad principles of feminist based interviewing, allowing for reflection on their impact on the data collected.

In obtaining qualified respondents, I was sure to acknowledge my personal relationship with potential participants and to avoid applying any pressure on them to take part in the research. Methods of avoiding pressure to participate involved extending only one request to participate. If a potential respondent appeared reluctant, yet agreed, I left it to them to contact me with an appropriate time. In the event that they did not contact me, I moved on to another participant to replace them. Having a large number of prospective respondents allowed me the opportunity to continue this process until I achieved the desired sample size.

During the actual interviews I interacted with the respondents as I normally would have in social situations, breaking for conversation on outside issues if they chose to 
discuss them. For example, one respondent asked me about a mutual friend's party and whether I had gone. Rather than sticking to the script and formalizing the process, I engaged in a small conversation with her about it and let her decide when to resume the interview questions. This technique was a conscious decision, following feminist research methods of interaction with respondents which attempt to dispel the power of the researcher over respondents (Oakley, 1981). Responses varied quite largely, in terms of length, to each question. This variation, to a certain extent, can be attributed to the probing which took place after responses were given. Probing after all responses to all open-ended questions took place varying from questions such as, "Is there anything else you would like to add?" to more specific probing on a particular point that was made in the response. Overall the interviews took place much like a conversation, rather than a question and answer session. I refrained many times from expressing my personal views on the responses although I did express sympathies for some of these. In particular, one respondent explained a situation of having hundreds of dollars stolen by a verbally abusive employer. I told her that I was very sorry to hear that this had happened and offered to assist her in accessing the proper forms to make a complaint to the Ontario Labour Board. Following this offer and extended sympathy, I found her demeanour slightly more open to make claims that might be perceived as 'complaints'. As research indicates, the serving industry is quite deeply entrenched with hegemonic masculinity and the result of these normalizations of subordination is a reluctance to be perceived as someone who complains. By employing feminist methods in my interactions with respondents, I was able to provide an attentive and unbiased space to air their 
experiences, thus securing what I believe to be more natural and uninfluenced representations of their experiences.

An important consideration in the selection of participants was whether to avoid those with whom I have had previous working relations or close social relations. Ultimately, I chose not to apply this method of avoidance as a determining factor in the selection of respondents. Having predominantly selected participants in the Ottawa area, it would have been very difficult to select participants with no personal social connection at all. The geographical restriction and my working history at several restaurants in the city prevented my ability to easily locate completely unknown respondents. Despite the unlikelihood of locating unknown participants, it was also decided to allow participants with close relationships to be interviewed as this would facilitate positive conditions for positive and non-hierarchical relations with respondents. All of the interview participants were aware of my history as a server prior to the interviews, removing some of the barriers which might have been in place if I acted solely as a researcher, rather than a peer. My experience as a server, and their knowledge of it also contributed to a more simplistic flow of dialog. Terms such as 'tip-out', '86', 'due back', and general knowledge of the industry, which would otherwise have required clarification and interjections in the interview process, did not require any pause in conversation. Had I intended to employ more hierarchical and traditional methods of distinction between the participants and researchers, these relations may easily have come into play negatively. However, as a feminist researcher employing feminist interview methods, my experience working with servers and relation as a peer acted well to negate unbalanced power dynamics. 
Having closely followed in trends of research on the interconnection between gender, legislation and precarious and subordinate labour, my thesis aims to ground these themes in contemporary practical experiences. While there does exist a moderate body of literature which focuses on case studies of restaurants and interview based approaches, these are predominantly focused on issues of sexuality and consumer tipping norms in the workplace (Creighton, 1982; Johnson, 2005; Liu, 2008; Hall, 1993; Maynard \& Mupandawana, 2009). These researchers are often able to link such issues to a broader theoretical framework, but they have yet to be analyzed in relation to legal regimes in Canada. Further, having worked as a server in restaurants for several years, it is clear in my experience that many of these studies (outside of the theoretical sphere) produce little information that would not be common knowledge to an experienced server. These works, however, have been helpful in grounding these knowledges in empirical data. As a result, the interview questions in this study have omitted questions that focus specifically on hyper-sexualization and customer tipping patterns in restaurants. Despite this omission, it should be noted that such themes were present in many of the respondents' interviews.

The questions attempt to provide information on several interconnected conditions of work for the respondents. The overall precarity of restaurant service work is gauged by questions 1,6 and 7. Question 1 asks respondents to determine how many restaurants they have worked for. This close-ended question was placed at the start in order to allow the respondents to begin the interview process with a sense of confidence in response. Gradually the questions work towards the central theme of this research, which is the impact of tipping on the precarity and insecurity of service work. These 
questions are intertwined with those on gendered hiring processes and promotional options in order to provide some concept of the ratio of women to men. As a result of the large body of literature which has already established the sexualization of women and gender roles within the restaurant industry, my research questions do not focus on this topic explicitly. This did not prevent the responses from including a multitude of experiences of sexual harassment and exploitation.

As the majority of social science research investigating restaurant work is based on case studies of individual restaurants, I have opted to focus more specifically on the individual experience rather than what has been experienced in one particular establishment. The precarity of restaurant employment means that most of the respondents have worked several jobs from which to draw experience and data. As an example, questions 3 and 4 ask for the ratio of men to women working in serving and managerial positions in all of their restaurant experience. For one of the respondents, this included a history of 17 different employers. This approach to interview selection also means that research data is produced without the knowledge of the employers and leaves little time for them to potentially 'clean up their act' prior to data collection or intimidate and pressure employees to omit certain experiences.

In order to interview servers who are presently employed and speaking directly about their employment conditions, many precautions were undertaken to secure confidentiality in the research process. Prior to participation, however, all participants were required to sign an informed consent form acknowledging the precautions undertaken and the remaining risks. This form has been attached an Appendix E. The primary issues of concern for participants revolve around the potential for punitive 
repercussions from both past and present employers as a result of sharing personal information, which would slander the reputations of such establishments. Another very important issue around confidentiality is the personal privacy of participants in sharing individual experiences.

In order to secure the confidentiality of the personal information of participants and past and present employers, I undertook several precautions around the interview process. All interviews took place in a private location not accessible to the public. Pseudonyms have been applied to both interview participants and employers. Any information, that distinguished an establishment uniquely from others, was omitted in an effort to further protect the confidentiality of respondents' former and present employers. Interviews were recorded and transcribed.

The potential for emotional harm was identified through the ethics process and addressed by measures of interview techniques. I recognized that asking about experiences of inequity in the workplace was a major source of potential emotional harm. For some participants this could invoke memories of emotional hardship. I aimed not to probe at respondents when an event seemed as though it may trigger an uncomfortable memory. Further probing was avoided in events where respondents appeared unwilling or reluctant to continue divulging information on specific topics.

Upon reflection on interview techniques, several methodological considerations emerged. I feel confident that the use of feminist interview techniques was a valuable tool for aiding in the comfort of the participants, and yielding fuller responses. By approaching the interviews from a fellow service worker position with respondents, as a fellow worker, interviews became more easily conversational and many participants took 
a dominant role in leading these conversations towards issues in the workplace that they felt were important. By allowing for a flexible conversation such as this, the participants were empowered to discuss issues that they deemed to be of importance. The result is that answers to the same questions vary substantially in length. No respondents were ever stopped or interrupted during any explanation. These techniques and my role as a fellow server aided overall in the quality of answers provided by respondents by making the process less formal and more accessible. Many times respondents would divulge information or use somewhat vulgar language which likely would not have been expressed had the interviewer been an unknown academic or male.

While using feminist interviewing techniques did prove to be substantially beneficial overall, I did note some concerns with the efficacy of the process during certain interviews. Three of the respondents asked me questions very early on such as: "Is that what you're looking for?" or "Did I answer that right?". The reason for the questions from the respondents may be interpreted in two separate ways. First, it is possible that the respondents were seeking approval in response to 'help' me as a result of our very amicable relations (Oakley, 1981; Cotterill, 1992). Second, they may have genuinely felt confused as to whether the answer to the question was appropriate. For example, Question 2 asks what style of restaurants servers have worked for and includes some examples of different styles. Some of the respondents would name styles outside of the examples and ask if they had answered the question properly as a result of going outside of the examples. This appeared to be a genuine question about the process rather than a question in an effort to seek approval. Question 3 asks for a ratio of men to women in serving positions and Question 4 asks for information on the ratio of men to 
women in managerial positions. Two of the respondents asked after question 4 whether their responses where what I was looking for. This concerned me in that the respondents demonstrated an interest in 'what I was looking for'. In hindsight, I believe that these questions may have been more efficient had I separated their order in the interview process rather than asking them back to back. While the concern over what I was "looking for" did arise in these two interviews, I do not believe that their responses varied from the true events which each respondent had experienced. Further, the diversity in the two responses indicates that the participants were not intentionally skewing data in an effort to seek approval. Overall, I believe that the benefits of using non-hierarchical feminist research methods far outweighed these concerns.

Balancing the relations with respondents in a manner that avoided hierarchical structure was managed predominantly through demeanour and use of conversation. However it must be acknowledged that the interviewer is always more likely to dominate a power dynamic and the interviewee is therefore more likely to be submissive in the process (Cotterill, 1992). Strong efforts were employed to curb any action or language, that may have assumed such roles, however certain dynamics could not be ignored. While the respondents were aware of my history working as a server they also were not in a conversation with me in my serving role. Rather they were experiencing me as an academic researcher. As mentioned previously, in one interview, I offered to help a respondent access forms from the Ontario Labour Board. Despite the intention to aid the participant and express sympathy, this may have also asserted a power dynamic of knowledge which would undermine the feminist approach. 
A final reflection, which needs to be addressed, is the interview questions. More consideration for the wording of the questions and ordering in which they were asked may have increased the validity of the data collected. As previously mentioned, the ordering of questions 3 and 4 may have hinted to participants that the research sought to establish whether or not positions in restaurants are gendered. While this revelation is not a threat to the information provided, it may have turned the minds of the participants towards the intent of the research rather than solely to their own experiences. Question 14 asks participants: "Do you feel like your tips are protected?". Many respondents expressed confusion in answering this question. Some interpreted it to mean physical protection, such as whether other workers could physically steal them. Others interpreted it to ask whether the stability of tips would be protected. The intent behind the question was to evaluate whether servers felt as though legislative standards and restaurant structures provided security around tips as wages for staff. This was not conveyed clearly through the question, which could have been more clearly worded. During the interview process I did not lead servers towards an answer around legislation because I wanted to gauge their knowledge of the law or lack thereof. Ultimately the responses did indicate a level of legal knowledge and an overall sentiment of the security of tips earned. However this could have been much more detailed and specific had the wording expressly identified legislative protections and structural issues. The following section will discuss the methods by which the data collected will be interpreted and analyzed. 


\subsection{Interpretation Methods}

In this section the methods of interpretation will be outlined, providing an overview of the process by which the data is interpreted and analyzed. The interview data has been divided into three central areas. These include precarity of serving in restaurants, gender roles, and restaurant structuring and controls and structures of tips. The data collected in each of these groups is intended to build upon pre-existing research in the area to develop new knowledges and ways of understanding. Specific methods of categorizing data will also be discussed in this section.

The first area to be addressed is the precarity of restaurant industry work for servers in Ontario. Leah Vosko has defined precariousness of work as a multi-faceted and layered concept requiring multiple approaches of understanding. Some of the central themes in defining precarious work in the $21^{\text {st }}$ century include limited social benefits, low wages, job insecurity and high risks (Vosko, 2006). Interview questions have been developed which assess these factors in restaurants. By interviewing women who have been employed by multiple establishments, the data is indicative of several restaurants in Ontario. Questions 1 and 7 assess consistency of employment, wages, benefits, and full or part time status of employment. These factors are assessed with relation to broader themes of precarity in the Canadian labour market for women to identify trends and discrepancies.

Within the analysis of the precarity of restaurant work, there also exists a separate layer of inquiry, which specifically deals with precarity caused by structures of tipping in restaurants. The chart below demonstrates the multi-dimensional analysis of precarity, which this research undertakes. Von Massow and McAdams have identified scheduling 
of good tip earning shifts and good tip earning sections as methods by which tips my be altered and made precarious by employers (Von Massow \& McAdams, 2012). Questions 6 and 8 specifically deal with these processes in restaurants. Questions 9 through 15 provide data on alternate sources that may cause tips to become precarious for restaurant servers, and also data on the participants' feelings towards these sources. Most importantly, question 11 asks servers to identify other means by which tips can be raised or lowered. This question explicitly aims to delve into the factors that are unique to the precarity of serving in restaurants. Following Vosko's understanding of precarious work as both individualized and industrialized, an analysis of the impacts of industry standards will take place simultaneously with an analysis that focuses on the more individualized experiences of the participants (Vosko, 2006).

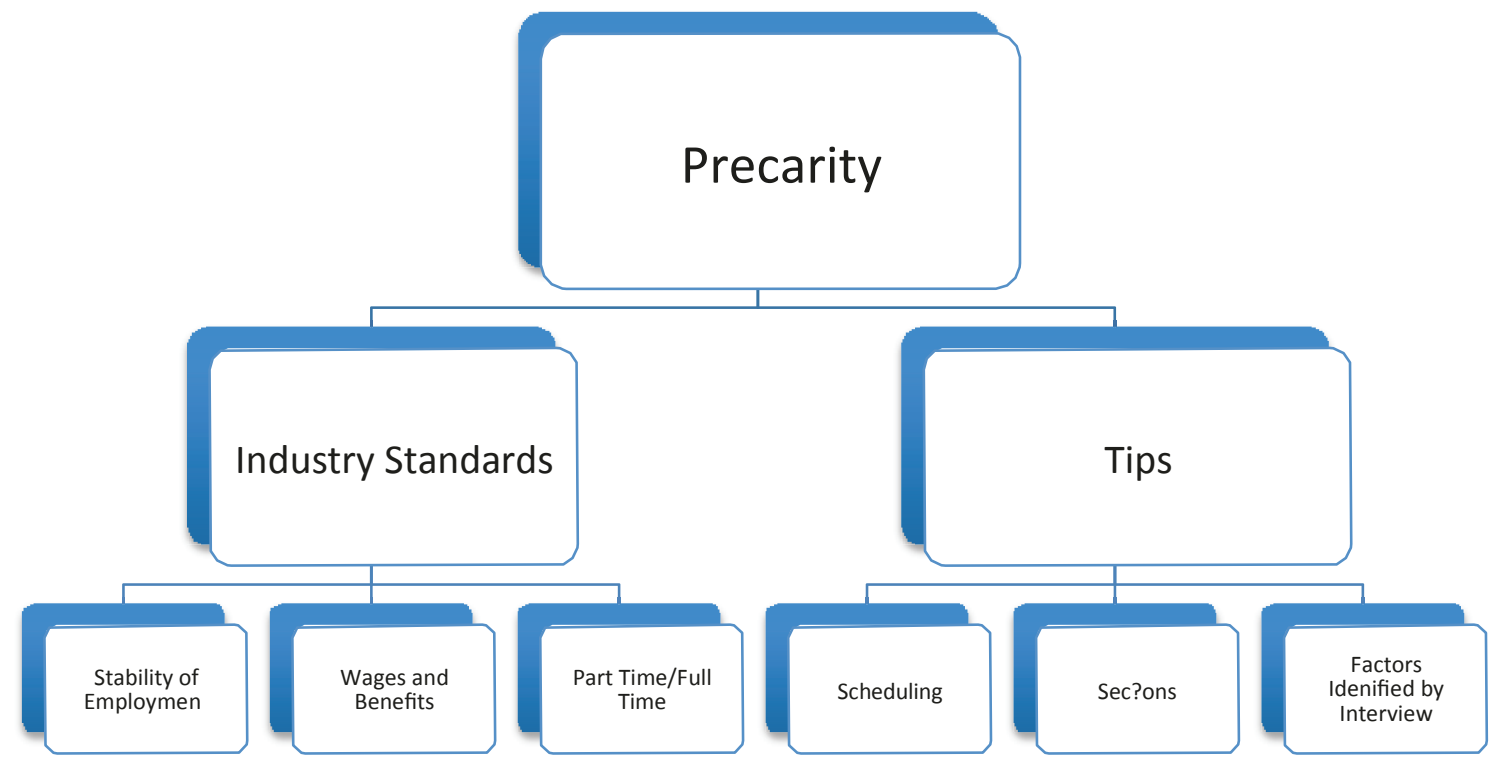

Following many streams of social science research, which focus on gender roles in restaurants, interview questions were developed to establish patterns of gendered 
hiring in Ontario restaurants. Questions 2, 3 and 4 investigate the predominant roles of men and women in job positions of restaurants. Question 2 specifically aims to determine if there is a gendered segmentation of men and women in higher and lower end restaurants in Ontario. Question 5 asks participants whether they consider gender to have had a role in being hired for serving positions. Building on existing studies around gender roles, the structures of restaurants will be analyzed within a context of gendered segmentation in the workplace. This analysis will apply a theoretical analysis of hegemonic masculinity to the restaurant industry and examine the influence of gender relations on broader structuring. Throughout the interview process, in explaining experiences around tipping and other issues that arose, respondents acknowledged many instances of gendered inequality and harassment. These experiences have been assessed in so far as they relate to themes of hegemonic masculinity in the workplace. These gender roles on the micro level will also be interpreted for their ability to be demonstrative of masculine hegemonic ratios in broader society and in the legislation that govern restaurants.

The final area of assessment undertaken is of the tipping structures in Ontario restaurants and the corollary implications of such practices. Questions 9 through 15 focus specifically on tipping regimes in restaurants. The precarity of tips, in this area of interpretation relates primarily to the assessment of who controls the variables that influence tips and how such control is exercised. Factors that have the ability to affect tip-earnings and are not in the power or control of the restaurant or its employees will also be determined. Methods of control that are formalized will be determined as well as 
those which are informal norms. The following chart demonstrates the stream of this method of analysis.

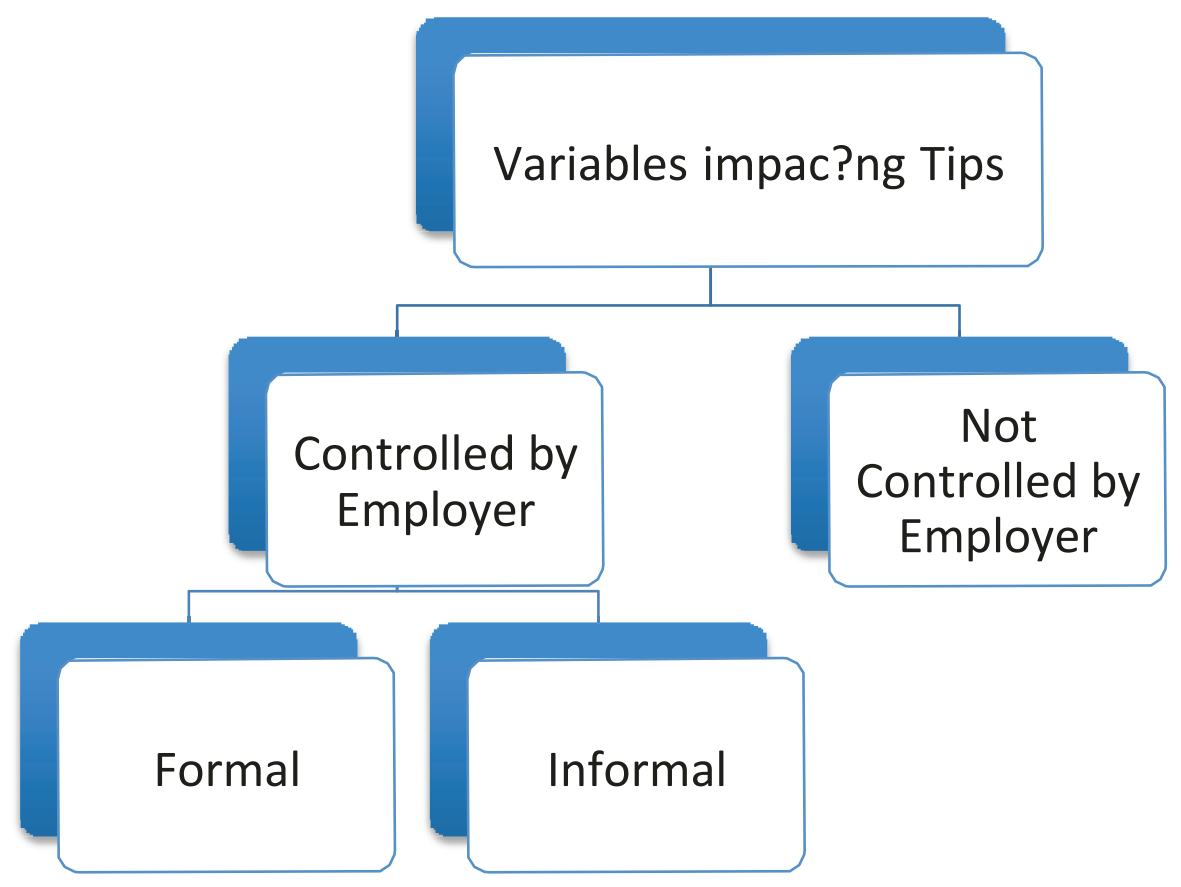

By applying this data to an analysis of the Ontario Employment Standards Act's omission of tipping from the legal definition of wages and failed attempts to provide legislated protections for servers' tips, the actual impacts for servers can be interpreted. Connections between legislative omissions and working conditions will allow for a meaningful analysis of potential legislative reforms. These reforms can be linked through the broader theoretical lens of hegemony to structures of gendered segmentation of work and labour legislation in an analysis that connects the relevant themes of each.

\subsection{Chapter Conclusion}

In this chapter the theoretical framework of masculine hegemony is established in relation to the gendered segmentation of labour and internal practices of exploitation of 
women in restaurants. This theoretical understanding will also be used to inform an analysis of Ontario employment legislation with respect to tips for servers. Next the interview methods and process are presented in the context of feminist research methodology. Finally, the structures by which research questions have been compartmentalized and sorted is explained in order to provide explanation for data interpretation. Chapter 5 embodies the application of these methods to the data provided in the research process. 


\section{Chapter: Gendered and Precarious Employment}

\subsection{Historical Context of Gendered Labour Segmentation}

In order to produce a meaningful understanding of contemporary developments in Canadian employment relationships and working conditions, it is integral to first explore the context in which employment standards originated. This section examines trends in the gendered segmentation of work in Canada and the corollary of such; gendered employment legislation (Fudge and Vosko, 2001). This historical analysis demonstrates that patriarchal divisions of labour are systemically reified by the regulatory standards which govern them.

The rise of the industrial revolution saw a clear division in labour between men and women. As much of the labouring positions created through industrialization required physical strength and patriarchal beliefs of the era supported notions of women as unsuitable for and incapable of such work, men predominantly overtook proletarian wage-labour ${ }^{9}$ (Burnette, 2008; Connell, 2010). In an article published on women's employment in 1901, this social ideal is expressly articulated:

"Whatever tends to unsex women should be frowned upon by public opinion, and, if necessary, prohibited by law. The great principle of the division of labor cannot be ignored in the apportionment of work to women and men... All employments which make women bold, fierce, muscular, brawny, in body or mind will be tabooed." (Finck, 1901, $\mathrm{p} 76)$

Tables 1 and 2 demonstrate the actual demographics of women's employment in this time. These statistics reflect the author's notion that certain forms of labour, which were

\footnotetext{
${ }^{9}$ Wage-labour can be defined as an employment relationship in which there exists an employer who provides financial compensation in the form of wages to an employee for a specified task (Marx, 1998).
} 
perceived of as more feminine, employed the majority of working women in the early twentieth century. For decades this trend was continued in Canada and elsewhere, establishing a gendered division of labour in which industrialized wage-labour has become normalized as men's work and unpaid or low-waged domestic work such as childcare and housekeeping has fallen to women.

\section{TABLE 1}

Leading Occupations for Women, 1891

\begin{tabular}{|l|l|}
\hline Occupation & Numbers \\
\hline Servant & 77,644 \\
\hline Dressmaker & 22,686 \\
\hline Teacher & 14,803 \\
\hline Farmer & 11,590 \\
\hline Seamstress & 10,239 \\
\hline Tailoress & 7,834 \\
\hline Saleswoman & 4,409 \\
\hline Housekeeper & 4,035 \\
\hline Laundress & 3,679 \\
\hline Milner & 3,277 \\
\hline
\end{tabular}

(Vosko, 2006)

Ideals around the types of work that should be occupied by each gender are also intertwined with norms around family structure and hierarchy. The gendered segmentation of labour industries saw women working in feminine roles, however the type of work itself was not the sole divisive factor. Wages and protections for specific 
industries varied greatly dependent on which gender predominantly occupied the job. Further, a presumption was built upon the notion that women should only occupy working positions in efforts to supplement the income of the male breadwinner of the family, therefore the financial needs of women were believed to be less than that of men (Connell, 2010). This stems from the belief that wages should reflect the sum needs of a family; ideally, the man of the household should provide income sufficient to support the entire family, otherwise referred to as a 'family wage'. Thus, wages for women became systemically structured at significantly lower rates (Kessler-Harris, 1988). In Canada, all provincial employment legislation of this time specifically dictated women's minimum wages to be lesser than that of men (Vosko, 2001).

\section{TABLE 2}

Leading Occupations for Women, 1921

\begin{tabular}{|l|l|}
\hline Occupation & Numbers \\
\hline Clerical & 78,342 \\
\hline Servant & 78,118 \\
\hline Teacher & 49,795 \\
\hline Saleswoman & 35,747 \\
\hline Housekeeper & 23,167 \\
\hline Nurse & 21,162 \\
\hline Dressmaker/Seamstress & 16,612 \\
\hline Farmer & 16,315 \\
\hline Textile Factory Operative & 15,193 \\
\hline Clothing Factory Operative & 14,470 \\
\hline
\end{tabular}


(Vosko, 2006)

Adding another layer to the structuring and development of 'women's work' is power and hierarchy. As it was believed that women did not hold the same financial need or physical capabilities to produce labour equal to men, a common belief developed that women should not hold positions of power or high social status. Political, academic and influential career paths were, thus, riddled with barriers preventing women's access. These barriers included formal legal restrictions from entering politics, voting and admittance to post-secondary institutions, as well as informal measures such as the 'glass ceiling' of corporate promotion. This term refers to the unseen barrier preventing women and from achieving workplace promotional success on the basis of gender or other social factors regardless of qualification (Connell, 2010).

A dramatic increase in non-domestic labour for women in North America occurred following the Second World War, troubling social understandings of 'women's work'. While then-normative constructs of domesticated femininity continued to be actively reproduced through advertising and media, the labour force entered a period of massive transformation (Sangster, 2010). With a majority of Canadian able-bodied men participating in military work during the war, many essential positions became vacant. In 1941 the Canadian Labour Supply Investigation Committee developed a structure by which to engage women in civilian labour to fill this gap (Pierson, 1983). As a result, Canada saw a rise in the employment of women for jobs which would normally have been deemed 'unwomanly'. In 1942 the Federal Government developed a Women's Division of the National Selective Service, which sought women to occupy specific employments in both public and private sector industries. Many provincial employment 
standards became relaxed to accommodate the influx of working women, allowing longer hours for women and positions in increasingly masculine jobs. Wages in war industries remained significantly lower for women, yet paid much higher than industries such as textiles and serving work which employed predominantly women in pre-war times. By 1944 the rate of employment for Canadian women became the highest in the country's history (Pierson, 1983).

The war's end in 1945, however, brought about another wave of intense change to labouring women in Canada. Ex-service men were provided priority job placements and it was nationally understood that women's labour was no longer necessary in many industries. Trades, which had become established as 'women's work' in pre-war times, such as clerical work and child-care, were now promoted to women facing unemployment (Pierson, 1983). Dominant conceptions of women's work were reestablished over the 1940s and 1950s, contributing to a decline in women's full-time employment and an increase in feminized, precarious and low-waged labour (Vosko, 2001). Based on the assumption that a woman's income is to be a subsidiary one to her husband's (Vosko, 2001), industries predominantly employing women continued to be marked by significantly lower wages and more precarity. This notion, however, ran in direct conflict with the recruiting strategy of the National Selective Service, which specifically sought unmarried young women under the age of 24 to enter the labour market in war times (Pierson, 1983). As a result many of the legislative standards directed towards married women earning secondary incomes, such as barrings from employment insurance and a gendered wage minimum, worked towards impoverishing young single women in Canada (Vosko, 2001). 
Further contributing to the dualism in labour standards and employment relationships between men and women was the development and proliferation of federal labour legislation and unionism following the Second World War. While many researchers view this era of social change and increased workers' rights as a success for the working class, an analysis of the gendered nature of this success reveals the deepening gap in women's employment equity. This is due to the basis on which such legislative standards were developed; the standard employment relation or SER. Bernstein et. al. define this relationship as "a full-time continuous employment relationship where a worker has one employer, works on the employers premises with direct supervision, and has access to social benefits and other entitlements that complete the social wage.” (Bernstein, S. et al., 2005, p. 204). The proliferation of unionism in Canada was dominated by industries which predominantly operated through SERs. Thus, as a historical analysis of women's labour demonstrates, the outpouring of labour rights and benefits won by trade unionism largely excluded industries occupied by women. As a result, the 1950s saw the beginning of the divide in labour and employment legislation. Labour legislation refers to federal employment standards and regulations which are now governed by the Canadian Labour Code (Canadian Labour Code, R.S.C., 1985, c. L-2). Resulting from an amalgamation of the Wartime Labour Relations Regulations (PC 1003) and the Industrial Relations and Disputes Investigation Act, the Canadian Labour Code was created in 1966. These developments in labour relations legislation through the 1950s and 1960s were established as mechanisms to govern the primary labour market. This refers to labour which falls under the breadth of the SER and is marked by full-time and continuous work. Such legislation governs collective 
bargaining, rights to trade union organization and dispute settlement (Canadian Labour Code, R.S.C., 1985, c. L-2). As unions became solidified and empowered through this era of legislative change, so too did the primary labour market and standard employment relationship. Consequently, this legislative reform simultaneously reified social constructions of the male breadwinner requiring a family wage and working women earning a subordinate and subsidiary wage.

On its face, federal labour legislation does not distinguish differential treatment of gender. However, the predominantly male membership of unions in the 1950s and 1960s distinctly marks this divide. As labour legislation became well established in post-war times, so too did provincial employment standards. While federal labour laws saw increased powers in collective bargaining and dispute resolution techniques which empowered workers to self-govern employment relationships, provincial employment standards largely dictated legal minimums (Vosko, 2001). Thus, a two-tiered construction of employment legislation in Canada was established in which the primary labour market saw increased powers in collective bargaining and stable working relationships while the secondary labour market saw little workers' rights outside of the ability to dispute predetermined minimum standards.

During the 1970s and 1980s, the primary labour market saw an influx of gender equality, as women increasingly occupied positions in more stable and full time employment. During this time the concept of a 'family wage', earned by the sole male breadwinner began to be troubled, as families increasingly needed dual incomes in order to sustain themselves. By 1987, the disparity in gendered representation in unions had decreased to only $3 \%$ contrasted to that of 1967 , which saw a $25 \%$ gap in overall union 
membership of men and women (Vosko, 2001). The large increase of women in fields of unionized work, however, did not mitigate the gap in traditionally feminized industries such as clerical work and childcare (Statistics Canada, 1994). Employments traditionally marked as women's work continued to predominantly employ women despite the increasing rates of women working in the primary labour market. Similarly, as women's employment rose in the primary market, it began to see more precarity through increased contract work and two-tiered collective agreements (Vosko, 2001).

As this research aims to assess women's employment in the secondary labour market, it is important to focus on those industries that are regulated by provincial employment legislation and are, therefore, governed by mandatory minimums rather than collective bargaining rights. While it is significant to acknowledge the recent growth in precarity for the primary labour market, it must be understood that the secondary labour market was constructed upon unstable and exploitative working conditions, which have further deteriorated with the declining stability of primary labour industries. Despite there being an increase in formal gender neutral legislative standards and even substantive equality in legal reforms, the actual representation of women in feminized industries, which are lower-waged and more precarious, has not changed substantially. As is demonstrated by Table 3, women continue to be more likely to be employed in traditionally feminized professions such as clerical, nursing and sales work despite a rise in women entering unionized positions in the primary labour market and a very slight increase in managerial positions. Thus, as women have become more present in the primary labour market, such gains have not impacted the gendered nature of professions in the secondary labour market. Research provided by Statistics Canada also indicates 
that women's employment is increasingly more part-time, significantly lower-waged and that women are more likely than ever to have multiple employers (Statistics Canada,

2010).

\section{TABLE 3}

Distribution of employment by occupations, 1987, 1999 and 2009

\begin{tabular}{|c|c|c|c|c|c|c|c|c|c|}
\hline \multirow[t]{3}{*}{ Occupations } & \multicolumn{3}{|c|}{1987} & \multicolumn{3}{|c|}{1999} & \multicolumn{3}{|c|}{2009} \\
\hline & Women & Men & $\begin{array}{r}\text { Women as } \\
\text { a percentage } \\
\text { of total occupations }\end{array}$ & Women & Men & $\begin{array}{r}\text { Women as } \\
\text { a percentage } \\
\text { of total occupations }\end{array}$ & Women & Men & $\begin{array}{r}\text { Women as } \\
\text { percentage } \\
\text { of total occupations }\end{array}$ \\
\hline & \multicolumn{9}{|c|}{ percentage } \\
\hline \multicolumn{10}{|l|}{ Managerial } \\
\hline Senior management & 0.3 & 0.8 & 21.0 & 0.4 & 0.8 & 28.2 & 0.3 & 0.6 & 31.6 \\
\hline Other management & 5.7 & 9.7 & 30.7 & 6.9 & 10.6 & 35.5 & 6.7 & 10.4 & 37.4 \\
\hline Total management & 6.0 & 10.5 & 30.1 & 7.2 & 11.3 & 35.1 & 7.0 & 11.0 & 37.0 \\
\hline \multicolumn{10}{|l|}{ Professsional } \\
\hline Business and finance & 1.9 & 2.3 & 38.3 & 3.1 & 2.7 & 49.3 & 3.6 & 3.2 & 51.2 \\
\hline Natural sciences/engineering/mathematics & 2.3 & 7.0 & 19.5 & 3.0 & 9.6 & 20.7 & 3.3 & 10.6 & 22.3 \\
\hline Social sciences/religion & 4.3 & 2.0 & 61.4 & 5.8 & 2.4 & 67.7 & 7.7 & 2.7 & 72.5 \\
\hline Teaching & 3.8 & 2.6 & 52.3 & 5.2 & 2.7 & 61.9 & 5.8 & 2.7 & 65.9 \\
\hline Doctors/dentists/other health & 0.9 & 0.9 & 43.1 & 1.1 & 1.0 & 47.3 & 1.5 & 1.1 & 55.2 \\
\hline Nursing/therapy/other health related & 8.3 & 0.9 & 87.1 & 8.1 & 1.1 & 86.3 & 9.1 & 1.2 & 87.1 \\
\hline Artistics/literary/recreational & 2.7 & 2.1 & 48.4 & 3.4 & 2.4 & 54.1 & 3.7 & 2.9 & 54.4 \\
\hline Total professional & 24.1 & 18.0 & 50.4 & 29.7 & 21.9 & 53.4 & 34.7 & 24.4 & 56.7 \\
\hline Clerical and administrative & 29.7 & 7.9 & 73.9 & 24.6 & 6.8 & 75.4 & 23.2 & 6.9 & 75.5 \\
\hline Sales and services & 30.0 & 18.4 & 55.2 & 29.4 & 18.6 & 57.3 & 28.9 & 20.1 & 56.9 \\
\hline Primary & 2.3 & 7.2 & 19.7 & 1.9 & 5.9 & 21.6 & 1.3 & 4.9 & 19.5 \\
\hline Trades, transport and construction & 2.1 & 28.9 & 5.2 & 2.0 & 26.1 & 6.0 & 2.0 & 26.3 & 6.4 \\
\hline Processing, manufacturing and utilities & 5.8 & 9.1 & 32.4 & 5.2 & 9.3 & 32.2 & 2.9 & 6.3 & 30.1 \\
\hline Total occupations $\underline{1}$ & 100.0 & 100.0 & 43.0 & 100.0 & 100.0 & 45.9 & 100.0 & 100.0 & 47.9 \\
\hline Total Employed (thousands) & $5,307.7$ & $7,025.3$ & $\ldots$ & $6,609.6$ & $7,797.2$ & $\ldots$ & $8,076.2$ & $8,772.7$ & $\ldots$ \\
\hline
\end{tabular}

(Statistics Canada Labour Force Survey, 2013)

These trends indicate that class is a factor which must be considered in the occupational gains and losses for women over the past three decades. It is clear that trends in lowwaged and gendered occupations have not substantially changed for women, yet trends in higher waged professions formerly more predominantly male-occupied are significantly altered. This rise in work for women in the primary labour market coincides with a rise in women's overall employment in Canada. Thus, an entry in the labour market of 
educated women who formerly did not work can account for this entry into the primary labour market. In an assessment of gendered gains in employment which acknowledges class, it becomes clear that substantial gains in employment equity have been won predominantly for women with access to paid education and thus of a higher socioeconomic class, while women who have historically experienced disadvantage continue to face such inequities and continue to be representative of a lower socioeconomic class.

As a result of a two-tiered approach to the governance of employment relationships in Canada, fields which have predominantly hired men for more stable employment have seen a proliferation of workers' rights through unionism and collective bargaining, while professions that are dominated by women's employment continue to be governed by legislated minimum standards. While many researchers believe that women have seen substantial gains in workplace equity, the static placement of women in industries which are marked by precarious and unstable employment demonstrates a severe divide in the class of women who have benefitted from such advancements. The following section of this chapter examines the ESA, demonstrating the methods by which such legislation reifies inequity and precarity in the secondary labour market.

\subsection{Contemporary Employment Standards in Ontario}

As the previous section demonstrates, there exists a long and deeply rooted history of gendered segmentation in the Canadian labour market. A central tool in this segmentation of labour and relegation of women's work to the more precarious secondary labour market has been provincial employment legislation governing workers' rights. As 
the majority of feminized professions fall under the breadth of the secondary labour market, it is provincially legislated minimum standards which predominantly govern women's work and act to systemically curb improved working conditions. This section provides a detailed analysis of the specific means by which the ESA can be applied and manipulated in its governance of low waged employees in Ontario.

The purpose of the ESA is to provide the rights and responsibilities of both employers and employees across Ontario workplaces (Ontario Ministry of Labour, 2012). Despite this legislation governing rights in employee-employer relations, Ontario workplaces continue to evade equity through processes which are quite arguably facilitated by the Act (Ontario, Legislative Assembly, $39^{\text {th }}$ Parl, $2^{\text {nd }}$ Sess, 2010). The purpose if this section is to critically assess the ESA in its application to low paid, nonunionized workers in order to better understand exactly whose rights are being served. To evaluate the application of the ESA and resulting impacts in the workplace, various factors will be explored. These include specific provisions of the Act, including recent and prior amendments, and the 'Employer Workbook' [briefly explain what this is] provided by the Ontario Ministry of Labour. These elements and mechanisms of the Employment Standards Act will be assessed through a theoretical lens of control and hegemony provided by Gramsci ${ }^{10}$.

The ESA was originally created in 1968 through an amalgamation of various employment standards statutes such as the Minimum Wage Act and Hours of Work and Vacation with Pay Act. A common and telling trend of these employment standards is their purpose of establishing 'minimums'. Currently, the ESA governs minimum wage,

\footnotetext{
${ }^{10}$ Chapter 3, Section 3.1 will provide a much more detailed theoretical analysis of hegemony as it relates specifically to serving in restaurants and the ESA.
} 
minimum vacation pay, minimum break periods, etc. (Ontario Employment Standards Act, 2000). In an analysis of labour and hegemony, Cox noted that employers will often make minimal sacrifices in order to ensure compliance. These sacrifices facilitate acquiescence through a false belief of employer flexibility and thus, the subordination that hegemonic relations demand. Very important to this analysis is the employers' balance of sacrifice and power, making sure never to provide the labourer any actual control (Cox, 1977). Thus, by mandating minimums, the ESA can be operated by employers as a mechanism to produce hegemonic labour relations.

The fact that the $E S A$ can be manipulated by employers does not necessarily mean that it is. For instance, many employers in Ontario pay wages well above the set minimums, offer lengthy paid breaks and shifts far less than the $E S A$ accepted 60 hour work week. However, for this anaylsis, non-unionized, minimum waged employees have been selected for review in order to understand the relationship between the ESA and hegemony for employees of those operating narrowly within the boundaries of the law.

Since its formation in 1968, the ESA has undergone various significant changes. The powers of different governments and political economic circumstances have made profound impacts on the Act's efficacy and ability to protect employees. At this point some of the major reforms of the ESA will be discussed in order to better understand how it is currently being applied and the ideologies behind such application. The first and arguably most substantial reform to be discussed is Bill 147 and its reworking of employment standards. Next, the more contemporary 2010 amendments of Bill 68 will be introduced to bring us to the current status and application of the Act in Ontario. 
In 2000, under the Conservative Harris government, employment standards were essentially "gutted" from existing legislation and reworked into the currently presiding Ontario Employment Standards Act, 2000 (United Steel, Paper and Forestry, Rubber, Manufacturing, Energy, Allied Industrial and Service Workers International Union, 2005, p. 2). Some important changes to the Act include: legal extension to 60 hours of work per week (by removing work overtime permits), legalized averaging of overtime hours, legalized vacation time in replacement of overtime pay, extension of pregnancy leave from 18 to 35 weeks, reinstatements ordered by employment standards officers as opposed to only the courts, and higher fines for corporate violators (The Employment Standards Work Group, 2001).

On their face, many of these appear to accommodate employees and support strict enforcement for employer violations. To the public, these amendments were generally welcomed and perceived positively. Harris' 'common sense' ideology of governance can be largely attributed to the positive public perceptions and subsequent implementation of Bill 147. During his premiership of Ontario a wide range of transformations took place under the premise of being plain and simple 'common sense' (Ontario, Legislative Assembly, $37^{\text {th }}$ Parl, $2^{\text {nd }}$ Sess, No 1,2000$)$. Similarly, there was a concentration on flexible work as the most efficient method of labour production. The central idea behind this was that flexible work would "promote cooperative labour-management relations and highly skilled, well-motivated employees" (Thomas, 2007, p. 109). Through this simplistic discourse on legislative change, the Conservative government effectively overpowered oppositions who sought to meaningfully evaluate the underlying and destructive implications of the proposed Conservative Bill. 
Each of the amendments proposed by Bill 147 was argued to be constructively adapting to the needs of social economic standards. It was the unions and political opposition who were quick to point out the flaws and underlying implications of this legislation. Although these groups were central to revealing the problematic nature of the Bill, it was the minimum waged, more vulnerable workers who felt the impacts of the ESA amendments most adversely. Some of the central concerns of the Bill brought forward by such groups included its facilitation of 60 hour work weeks for employees and flexibility in overtime pay.

The most obviously uncontroversial of the above listed amendments is the extension of pregnancy leave. Harris's Conservative government was well aware of this and took measures to ensure that extended pregnancy leave was front lining public information on the Act and opponents were portrayed as unsympathetic to women and children. In a battle over such use, the Liberal government accused Conservatives of holding pregnancy leave "hostage" to the more controversial 60 hour work week and flexible overtime pay (Ontario, Legislative Assembly, $37^{\text {th }}$ Parl, $2^{\text {nd }}$ Sess, No 1,2000$)$. In fact, this was a serious and valid point because it had already been decided by a previous Bill to increase pregnancy leave. By incorporating the predetermined pregnancy Bill into Bill 147, the Conservatives effectively did hold legislation, which should have never been up for debate, hostage to their more 'flexible', 'common sense' capitalist standards.

As predicted by the Bill's opponents, employers quickly took advantage of the newly flexible overtime work standards to the detriment of their staff (Thomas, 2007). Through a method coined as 'Toyotaism' Ontario Toyota automotive plants began to institute work weeks of mandatory overtime hours (above 48 hours per week). By 
implementing excess hour agreements as a compulsory requirement of the hiring process, employers at the Toyota plants (and presumably many other institutions) were able to legally bind staff to perform excessive amounts of labour. In a Labour Relations Board Decision initiated by complainants from Toyota, it was determined that all employees hired prior to the Bill 147 amendments to the ESA were entitled to compensation and all of those hired post amendments were not (Thomas, 2007). This decision, as noted by Thomas, marks a monumental shift in ideological approaches to labour standards which disproportionately impacts the non-unionized, minimum waged employees (Thomas, 2007). Undoubtedly, the reformation of the ESA in 2000 broadened coercive employer control and effectively silenced resistance to such control.

The massive changes made to employment standards in 2000, under the Ontario Progressive Conservatives, were largely challenged by the Liberal Party, under Dalton McGuinty. When the Liberal's came to power in 2003, it was presumed by much of the public that labour standards would no longer be at risk of further decline. It was not until 2010 that the next major changes to the ESA took place. In promotion of the Open for Business Act, Bill 68, the Liberals stated:

“..the Open for Business Act, if passed, will address long-standing concerns of the business community. It would save businesses both time and money while continuing to provide appropriate government oversight." (Ontario, Legislative Assembly, $39^{\text {th }}$ Parl, $2^{\text {nd }}$ Sess, 2010)

According to the Liberal Party's platform, amending the ESA would promote faster resolutions to employee complaints while facilitating the need to keep Ontario businesses open and operational. The changes to the legislation included: employee obligation to notify employers of complaints before filing with the labour board and new powers given 
to employment standards officers to informally mediate complaints and deem them to be withdrawn on such basis. As was argued by the New Democratic Party, these changes would severely and disproportionately impact low paid, non-unionized workers (Ontario, Legislative Assembly, $39^{\text {th }}$ Parl, $2^{\text {nd }}$ Sess, 2010). Under the guise of promoting good business and fewer complaints (therefore less backlog and more resolutions) the Liberal government was able to push this Bill through the legislative assembly and into the ESA.

The discourse surrounding this set of amendments was largely premised around the prosperity of Ontario businesses and efficacy of the Labour Relations Board and ESA officers to expediently deal with complaints. Clearly the inability of employees to lodge complaints without first notifying employers is problematic and especially so when power imbalances are being exploited (which is often the exact reason for the complaints in the first place). This Bill overtly contrasts with equitable treatment of employees and much like the implementations of 2000, it created barricades between employees' ability to access just resolutions.

Although both major changes to the $E S A$ were quite foreseeably problematic, each was implemented and remains in force today. It is clear through this analysis that Ontario employment standards are developed within a broader scope of goals and needs. It has been illustrated that the goals of 'business' and provincial prosperity will more often than not override the needs of employee rights. In this sense, hegemony can be found embedded in the very discourses which create the legislation; law makers have corporate minded goals and business interests while minimum waged, overtime working employees are unlikely to even be aware of legislative changes until they are hit with the effects of them. 
A proper and revealing extension of the $E S A$ provisions is the publication: 'Complying with the Employment Standards Act (ESA): A Workbook for Employers' (Ministry of Labour, 2012). Through an analysis of this employer workbook, the ESA guidelines will be compared to both employee and employer needs.

One of the first notable features of this booklet is its audience. Both employees and employers are expected to be informed of and in compliance with the ESA. However, only employers have been the recipients of comprehensive breakdowns of the legislation via workbooks. Throughout the workbook, language that appeals to business owners is applied. One key example is the preliminary statement: "Good working conditions benefit both employees and business owners. Studies show that when employees are satisfied at work, they perform better and stay longer. Knowing how to comply with the ESA - the goal of this workbook - simply makes good business sense!" (Ministry of Labour, 2012, p. 5). Instead of ascribing the business owner some sense of moral and ethical decency, the workbook plays to their capitalist needs by sending the message that ESA compliance can be used as a mechanism for highly efficient labour production.

The language and propositions set around 'Miscellaneous Things to Remember' in the workbook is also a good indicator of the ideology behind it. A more suitable title for this section might be 'Shortcuts and Loopholes for Exploitation'. The workbook, here, explains to employers that it doesn't matter how late your staff works, you never are obligated to provide them with transportation home. Similarly, wages never need to be provided for a commute to and from work under the ESA. Finally, if an employee needs training to fulfill a promotion within the company, the employer will never be obligated 
to pay the employee for such training hours (Ministry of Labour, 2012, p. 19). These sorts of messages are found throughout the workbook, providing employers with the resources necessary to deny employee requests of safe and fair workplace accommodation.

On the final page of the $E S A$ employer workbook is a small and interesting slogan. It reads: "Say YES to ES" (Ministry of Labour, 2012, p. 58). In each of the sections of the workbook is a series of questions to help an employer understand whether or not they are in compliance with the ESA, followed by a box to check for 'YES' and for 'NO'. The final page of the workbook and its slogan, whether or not it is intentional, implies that ESA employer compliance is optional. This, in addition to its language which advocates that compliance will promote 'good business' is very much targeted at appealing to businesses. The workbook can be thought of as an apparatus of the political hegemonic relations from which it was derived: its goal being to explain and engage employers in applying minimums and abstentions in order to best keep the provincial economy on the rise.

Having now established many of the broader ways by which the ESA favours employers and business above the welfare of the employed, a more specific analysis of its application to the restaurant industry and tipping regimes will take place. Taking into consideration the statistics of Table 3 which clearly establish an overrepresentation of women in sales, service and administrative roles, all of which are predominantly nonunionized and governed by the ESA in Ontario, it must be noted that women, especially in such industries, are more likely to experience hegemonic controls and inequities resulting from the administration of the ESA. Women in the restaurant serving industry 
are particularly at risk of facing workplace inequity, arguably facilitated by the ESA, as almost $80 \%$ of serving staff in Ontario are women (Statistics Canada, 2006).

Arguably the most overt inconsistency in the ESA's governance of this industry revolves around wages and tipping. Ontario employment regulations specifically and directly ensure that wages in the restaurant industry remain substantially below any other by designating a legal minimum wage lower than that of any other profession for tipearning servers. Currently, this amounts to $\$ 9.55 /$ hour as opposed to the otherwise mandated minimum of $\$ 11.00 /$ hour. It is an unspoken assumption of the legislation that tips earned by serving staff will supplement the low wages substantially enough to ensure that servers are not paid less than the equivalent of the province's minimum wage for all other kinds of work. While the precarity of gratuities problematizes this belief, it is further disturbed by the lack of regulation, which exists around tipping in Ontario. The ESA explicitly excludes tips from its legal definition of wages, ensuring that this regulatory Act is not accountable for any oversight of the supplementary income, the existence of which it simply assumes (Ontario Employment Standards Act, 2000).

In recent years, inequities around tipping structures in restaurants have surfaced in political debates at the Ontario Legislature. First introduced in 2010, as Bill 114, An Act to amend the Employment Standards Act, 2000 with respect to tips and other gratuities (short title, Protecting Employees' Tips Act), the provincial NDP attempted to amend the ESA by restricting employers from directly taking a portion of tips from serving staff. This Bill would add a new section to the ESA, as Part V.I: Tips and Other Gratuities, which would state, “An employer shall not take any portion of an employee's tips or other gratuities." (Bill 114, An Act to amend the Employment Standards Act, 2000 with 
respect to tips and other gratuities, First Reading, October 6, 2010, 39 ${ }^{\text {th }}$ Parliament, $2^{\text {nd }}$ Session). While the Bill does not address the broader implications and inequalities caused by excluding tips from the protections provided to all other wages, it does prevent a major source of inequity resulting from the powers that restaurant owners have to directly withdraw tips from serving staff. This practice has become common in many Ontario restaurants, where a percentage of each employee's sales is added to the amount owed to the business after every shift. As an example, a server who sells $\$ 920.50$ at a downtown Toronto restaurant is required to pay to the restaurant $\$ 23.02$ in 'Tip-Outs' which are withdrawn from the total tips owed to the server and deposited directly to the owners bank account. Attached as Appendix A is the daily sales read of a server at such a restaurant which clearly states the total tips earned for the shift, the deductions of these tips and the final amount provided to the server after the restaurant has taken their share. On a busy shift with high sales servers at such restaurants are forced to hand over around $\$ 60.00$ of tips earned. While many more subtle methods of exploiting servers' tips exist in the industry, this is easily the most obvious method by which restaurant owners profit from the exploitation of staff.

The first reading of Bill 114 was met largely with support from all parties at the legislature, as it is quite unconscionable for any politician to argue in favour of such an overt injustice. Of course, some were able to fit in acknowledgements of the "demands on businesses to survive in this highly competitive hospitality industry", however these concerns were quite padded with sympathies to the "low-waged workers of Ontario" (Ontario, Legislative Assembly, Official Reports of Debates (Hansard), $39^{\text {th }}$ Parl, $2^{\text {nd }}$ Sess, No 10 (28 October 2010) at 1550 (Hon Steve Peters)). Despite wide support and 
quickly being referred, the Bill ultimately died under consideration of the Standing Committee. In June of 2012, the same exact Bill was brought to the Legislature, again by the NDP, as Bill 107. With no debate in its second life, the first reading was quickly carried.

NDP MPP, Michael Prue, responsible for the Bill's creation, was, however, met with considerable opposition to the Bill in the media, despite its relatively unopposed position in the legislature. Leading up to its second attempt in the Ontario legislature, the Labour Minister publically denounced the Bill, stating, "When you are a good server, it's a very competitive environment. You can go where you can get the best deal”. The Minister went on to speculate that in her opinion, this is not a widespread practice (CBC News, 2012). Industry professionals and scholars also refuted the Bill, but for different reasons, stating that the tip out process is so fundamental to the restaurant industry that the Bill would seriously compromise its sustainability (Von Massow \& McAdams, 2012). The Minister of Labour's comments reflect the stance that the employee has a freedom to enter and leave employment contracts at will, negating the inherent power dynamics in the workplace and gendered nature of table serving. Similarly, the industry professionals ignore power imbalances, yet also support that the process of tipping-out is absolutely systemic within the industry and unavoidable to serving staff. As a result of the Liberal government's prorogation of parliament, the Protecting Employees' Tips Act, was again put on the backbench of parliamentary priority and ultimately defeated as it was not scheduled post-prorogation.

In April of 2013, the Bill was, again, brought forward to the Ontario legislature. As the Protecting Employees' Tips Act quickly ascended to the standing committee and 
towards a third reading, voices of opposition and dissent began to emerge. First to speak against the Bill's intent was James Rilett, vice-president, Ontario, of the Canadian Restaurant and Foodservices Association (CRFA). Mr. Rilett's opposition was supported by his interpretation of the Bill's unintentional outcomes, one of which would be the "negative impression of owners" which would result from a law that applies to all restaurants (Ontario, Legislative Assembly, Official Reports of Debates (Hansard), 40 ${ }^{\text {th }}$ Parl, $2^{\text {nd }}$ Sess, No 10 (27 November 2013) at 1210 (Hon Lisa McLeod)). The vicepresident of the CRFA went on to misstate the legal minimum wage of servers in Ontario while arguing for access to their gratuities in order to supplement to gross income of restaurant owners. In another presentation by the Tourism Industry Association of Ontario, Ms. Beth Potter proposed several amendments to the Bill, which completely counter its fundamental purpose. These included an allowance for business owners to deduct from serving staff the cost of processing debit and credit card transaction. Another amendment would allow for business to garnish tips as wages (Ontario, Legislative Assembly, Official Reports of Debates (Hansard), $40^{\text {th }}$ Parl, $2^{\text {nd }}$ Sess, No 10 (27 November 2013) at 1240 (Hon Lisa McLeod)). The irony of the second amendment is that, should it be implemented, the ESA would explicitly exclude tips from the legal definition of wages for protections yet also include tips as wages for the purpose of garnishment by employers.

In debate, Progressive Conservative MPP, Toby Barrett spoke as the official opposition of the Bill, advocating for clarifications on definitions and meanings (Hansard), 40 ${ }^{\text {th }}$ Parl, $2^{\text {nd }}$ Sess, No 10 (4 December 2013) (Hon Lisa McLeod)). Several amendments were proposed by the Progressive Conservatives, largely expanding the 
Bill's scope while also narrowing its intended protections. Following debate several of such amendments were made. Attached as Appendix B.1 and B.2 is Bill 49 in its original and amended form. While amendments to the original, one sentence, Bill do provide for clarity which could aid in its implementation, some, such as exceptions provided by sections 14.1 (8) and 14.1 (9), allow owners to force staff to provide a portion of tips if the work is shared with owners. As has been demonstrated by analysis of the ESA Handbook, Ontario's employment standards are riddled with loopholes to compliance. It is clear that the interests of business, under the guise of provincial economic welfare, were able to infiltrate these debates, even in circumstances such as this, where the inherent intent of the Bill is to prevent corporations from exploiting staff. Once again, despite having been altered substantially towards the right, after being ordered for a third reading and only one step from receiving royal assent, the Bill was defeated as a result of the June 2014 provincial election.

Significant to the process, advocacy, and debates around this recurring legislative battle is the complete omission of any recognition of gendered inequities in the serving industry. In none of these debates was the overrepresentation of women in serving positions acknowledged. The next section of this chapter explores the systemic exploitation of women in the restaurant industry and its deep rooted relationship with structures of tipping and tip allocations.

\subsection{Literature around tipping and sexualization in the restaurant industry}

Despite the Ontario Legislature's complete omission of it, academic researchers, particularly in the social sciences, have engaged in studies around gender roles and sexual 
exploitation in restaurants for decades (Rasmusson, 2011; Lerum, 2004; Hall, 1993; Johnson, 2005; Creighton, 1982; Gilbert, Guerrier and Guy, 1998). The intersection of this line of research with studies of Canadian employment legislation that systemically fails to equally protect women, reveals gendered social controls which are deeply embedded in both legislation and social customs. Many of the case studies and interviews of restaurant workers are demonstrative of the negative impacts of tipping structures and the need for meaningful legislative reform.

Citing an extensive amount of literature, Hall's 1993 article, Waitering/Waitressing: Engendering the Work of Tables Servers, describes a myriad of methods by which the gendered segmentation of labour reifies gender roles in restaurants. These methods are inclusive of hiring for positions based on gender and allocating tasks which reflect a worker's gender (Hall, 1993). Systemically, these methods of work allocation and structuring have served to place men in more powerful and better paid positions, while women are continuously hired into the precarious work of serving tables (Hall, 1993).

Research and statistical analysis also support that, while women occupy the overall majority of serving positions ( $78 \%$ in Ontario), men occupy the majority of high end serving positions and produce more income (Statistics Canada, 1996). Annual income for male servers in Ontario is $25 \%$ higher than their female counterparts. Similarly, male bartenders earn $23 \%$ more than female bartenders in Ontario annually (Statistics Canada, 2006). This disparity in income by gender supports the notion that restaurants pay staff above the minimum server's wage are more likely to hire men, while women are more likely to occupy positions in restaurants which operate by paying the 
server's minimum wage in Ontario. Further, the majority of restaurants which employ staff for the servers' minimum wage are more likely to engage in practices of precarious employment such as shiftwork, seasonal occupation, part-time employment and minimum wages. The conditions of such workplaces foster environments where gender roles are reinforced and hierarchical constructs continue to place women at the bottom.

More broadly, case studies have proven that sex discrimination in hiring exists systemically in restaurants, finding that $80 \%$ hired for low-earning serving positions are women and $85 \%$ hired for high-earning serving positions are men (Neumark, Bank, Van Nort, 1996). Neumark, Bank and Van Nort note that in high end restaurants both the pay and the gratuities earned are substantially higher than those of lower end restaurants. In such establishments women are generally hired to hang coats and hats without the option of promotion; whereas in lower end restaurants, no such position exists (1996). Thus, women's positions are consistently at the lowest possible pay grade.

Similar to feminized and sexualized professions such as cheerleading and flight attending, much research has been produced which analyses the gendered sexualization of waitressing (Hall, 1993; Rasmusson, 2011). Intertwined with this analysis of sexual exploitation also exists an extensive body of research analyzing the prevalence of sexual harassment in the restaurant industry (Lerum, 2004; Guiffre and Williams, 1994; Gilbert, Guerrier and Guy,1998). Many of such researchers have directly connected high rates of sexual harassment and blurred conceptualizations of unacceptable sexual behaviour to the intensified sexualization of waitressing (Guiffre and Williams (1994). Hierarchical structures in restaurants are also attributed to these practices. As men are privileged with predominantly higher status positions, it is commonly women who are dictated to follow 
particular roles. These roles are often inclusive of uniform standards which sexualize feminine body features (Creighton, 1982) and tasks associated with table serving in restaurants which are inherently gendered in nature (Rasmusson, 2011). Statistics demonstrate that working in the restaurant industry increases a woman's likelihood of being sexually harassed. Most notably, women are more than twice as likely to experience insulting sexual comments and sexual gestures while working in restaurants. While the results of this survey pertain to sexual harassment more broadly, it is important to note the different kinds of sexualization and sexual harassment that occur in restaurants. These can be broken into two main categories; sexual harassment by coworkers and sexual harassment by customers. While the two are likely to overlap in nature and cause, there are several important factors which separate them.

It has been widely established by social researchers that there is a power imbalance, which exists between the customer and server in restaurant work (Hall, 1993; Lerum, 2004; Guiffre, 1994; Williams, 1994). This imbalance is further exacerbated by tipping structures which allow each guest to independently affect the wages earned by the server. Case studies have also established the existence of employer pressures on serving staff to flirt and demonstrate a submissive demeanor with customers (Hall, 1993; Rasmusson, 2001). This expectation, coupled with provocative uniform standards and precarious wages facilitate a working environment which is both ripe with sexual exploitation while also blurring the lines between what is considered sexual harassment and what is an expectation of the job. Research indicates that many servers who have experienced what can legally be defined as sexual harassment do not perceive it as such 
(Chai-Jeng, Kliener, 2011). In many restaurants, a sexual advance from a guest to a server is considered a "job well done" by management (Hall, 1993).

Lerum's recent ethnographic research around sexuality and camaraderie within restaurants reveals social and cultural features, which she argues are reflective of organizational structures around gender in the restaurant industry (2004). The study illustrates the use of hyper-sexualized interactions, through language, gestures and physical exchanges, between staff acting as mechanisms bonding them to each other. Threats of "rape" and what would normally be considered derogatory language such as referring to women working as "prostitutes" were noted as having become socially normalized in the workplaces (Lerum, 2004, p. 761). These interactions are further extended to include physical sexual touches in the workplace. In many restaurant workplaces to become the recipient of overtly sexual behaviour is a form of acceptance among staff. The boundaries of these actions, however, are not discontinued based on the hierarchical structures of the workplaces. In many situations, Lerum described gendered and sexualized exchanges between management and workers. Thus the workplace environment in many restaurants operates regularly through social interactions which would otherwise be deemed inappropriate and likely be perceived of as cause for legal repercussions. As a result, the staff have a skewed perception and tolerance of inappropriate sexual workplace behaviour. This acceptance of a hyper-sexualized workplace facilitates an environment, which makes it difficult to express unwanted sexual interactions and increases the likelihood of both wanted and unwanted sexual behaviour. 
While social science researchers have largely tackled topics around social interaction and sexuality in restaurants, business and industry researchers have studied tipping regimes in modern restaurants. As some social science researchers have acknowledged in the study of sexual exploitation in restaurants, tipping is a tool which exacerbates many of the inequities around customer relations and precarious wages (Hall, 1993; Rasmusson, 2001). From an industry perspective, tipping regimes are largely perceived of as problematic on the basis of efficiency and profitability of restaurants (Von Massow \& McAdams, 2012; Maynard and Mupandawana, 2011; Liu, Chu-Mei, 2008). Many of the industry studies related to tipping revolve around customer service satisfaction methods and provide little analysis from a lens which seeks justice for serving workers.

Von Massow and McAdams have produced some of the leading research on tipping regimes in Ontario through the University of Guelph Sustainable Restaurant Project. One of the central themes of this project's analysis is that of tipping regimes and their impact on industry productions and worker efficiencies (Von Massow \& McAdams, 2012). This research comes as a response to the, previously discussed, Protecting Servers' Tips Act in an attempt to provide knowledge from an industry perspective. While Von Massow and McAdams have applied interview based research methods in some forms, it must be acknowledged that their work comes from the perspective of industry professionals and thus is not intended to be constructed as a holistic account of workers' perspectives.

Concerns discussed by Von Massow and McAdams revolve largely around tip sharing structures in restaurants. Tip sharing is separate from, yet very similar to, 
previously explained 'house' or 'management' tip-outs. This is the process by which serving staff share tips with restaurant hosts, bussers, bar-backs, kitchen staff and servers' aides. Just as some servers are forced to provide restaurant owners with an amount of their tips-earned based on a percentage of total sales, the majority of servers are also expected to provide a percentage to all other restaurant staff. These percentages range from roughly 1.5 to 6 percent of total sales (Von Massow \& McAdams, 2012). Von Massow and McAdams acknowledge some of the overt problems with this system. Most obvious of these is that tips are not guaranteed and tip sharing amounts are determined on total sales rather than total tips earned. As a result, servers are the only staff paid less than the otherwise mandated legal minimum, while also being forced to supplement the income of other workers with tips which are unpredictable and not guaranteed to them. The researchers acknowledge that "tip sharing is an attempt to make the best of a bad system" (Von Massow \& McAdams, 2012, p. 7). However, they do advocate in opposition of the Protecting Servers' Tips Act by reasoning that the Bill would take away the ability of restaurant owners to equitably share tips amongst staff. While the intent of the Bill is to prevent owners and managers from dipping into servers' tips, Von Massow and McAdams argue that it also removes the ability to share tips amongst staff and disproportionality provides servers with much higher wages. One of the examples that they provide is a decrease in workers seeking management positions as a result of servers' tips producing higher over all income.

Most relevant of their findings in this study is a small discussion of practices of power and control exercised by management over tips earned by serving staff. They describe the examples of good tip earning nights and sections. Servers who are preferred 
by management may be provided with shifts that are known to yield higher tips. Further, servers who are being punished by management could be allocated a section of tables which are known to yield lesser tips (Von Massow \& McAdams, 2012). 'Table hogs' are an example provided of methods by which servers may assert dominance over each other in tip earnings. A 'table hog' is a server who claims more tables than others throughout the shift, thus selling more with the intention of earning more in gratuities. While these examples are helpful and important to any discussion of the relationship between tipping and exploitation in restaurant service work, Von Massow and McAdams have yet to more deeply explore these topics. Much more research is required into the methods by which tips are controlled and the linkage between this dominance and control with gender and

sexual exploitation in restaurants. The following chapter will provide the theoretical lens of hegemony and its extension to hegemonic masculinity from which dominance and control will be analyzed in the restaurant context. Further, methods of performing data collection and interpretation will be articulated.

\subsection{Chapter Conclusion}

This chapter discusses the debates on gendered and exploitative labour practices. It outlines the historical context of gendered and precarious labour for women. Conceptual analytical tools such as the standard employment relationship and precarious labour are defined, providing a groundwork of knowledge around the entrance and marginalization of women in Canadian labour markets. Next, the Ontario Employment Standards Act is investigated and its ability to be applied as a mechanism of hegemonic coercion is discussed. Finally, the gendered and sexualized nature of restaurant work is 
contextualized within research around both tipping processes and gendered workplace standard in restaurants. The intersection of these lines of research reveals that gendered precarious working relations, legislative practices and individual industries exist and facilitate one another in the production and reproduction of masculine hegemony. 


\section{Chapter: Data}

\subsection{Precarity of Employment for Servers in Restaurants}

As described in the previous chapter, an approach to understanding the precariousness of work must be multi-faceted and layered (Vosko, 2005). In order to assess the precarity found in serving positions in restaurants, I began each interview by asking servers about how many restaurants in which they have worked. This is the only close-ended question of the survey, but it yielded quite meaningful results. Most notably, five of the respondents asked for a pen and paper in order to tally up the total number of employers they have had. Many more of the respondents would stop further into the interview to change the total to a higher number, upon recalling a certain experience. The average number of restaurants in which the servers had been employed came to 11 . The highest number of employers was 17 and the lowest was 6 . None of the women interviewed appeared physically to be above the age of 30. Many self-identified as below 25 at some point during the interviews ${ }^{11}$. Servers are required by law to be 18 years of age or older, meaning that the participants could not (assuming ages to be 30 or below) have been employed in the restaurant industry for more than 12 years despite such high numbers of employers per server.

Question 7 first asks servers whether they have worked full time for any of the restaurants in which they have been employed. All respondents answered in the positive to this question. However, the subsequent questions and probes trouble the original response and render it somewhat unreliable. When asked the duration of the full-time employment, the average length of time offered by the respondents was 2 years, 3 years

\footnotetext{
${ }^{11}$ Age was not a determining factor in the interview selection process nor was it an interview question.
} 
being the longest time period and 1.5 years being the shortest time period. In responding to this question, many respondents reflected that the concept of 'full-time' employment in restaurants does not actually mean that you are consistently working 35-40 hours each week. As one respondent noted, "I had five shifts a week. That didn't mean I'd get the hours in though.". Another explained, "You are never guaranteed the hours. Sometimes full-time would mean 25 hours.". The scheduling process in restaurants was explained as one that provides shifts on the basis of a starting time, without a scheduled time to end. The shift may not begin at all or may last only a few short hours depending on the volume of customers. Thus, to say that $100 \%$ of respondents were employed at full-time hours for an average of 2 years would be false. What can be said is that $100 \%$ of respondents considered themselves to be full-time employees, despite not working a regular schedule of above 30 hours per week, for an average of 2 years.

Despite having been employed for up to 3 years on a 'full-time' basis, not a single respondent had ever been paid more than the legally mandated minimum wage for liquor serving employees. Similarly, all but one of the servers interviewed had never received benefits from an employer. This server explained that after one and a half years, she was offered a partial benefits package. The results of questions 1 and 7 have been complied into Table 4, below.

\section{TABLE 4}

Results of Questions 1 and 7 (on Stability and Duration of Restaurant Work)

\begin{tabular}{|l|c|}
\hline Average Number of Employers & 11 \\
\hline Have been Employed Full-Time & $100 \%$ \\
\hline Average Duration of Full-Time Employment & 2 years \\
\hline
\end{tabular}




\begin{tabular}{|l|c|}
\hline Have received Benefits & $10 \%$ \\
\hline Paid more than Server's Minimum Wage & $0 \%$ \\
\hline
\end{tabular}

In order to measure the precarity of income resulting from tipping structures three central questions were asked addressing this issue. Questions 6 and 8 ask the servers to explain the specific processes by which sections and scheduling are determined. These are two of the major factors impacting tip earnings, as identified by Von Massow and McAdams (2012). When asked to explain the process of scheduling and shift allocation in restaurants, all of the servers stated that seniority was the main determining factor. As one of the respondents explained, "They had a list and, based on seniority, they would give you better shifts. In some places, newer people would always be put on breakfast because there isn't as much sales, so you don't make as much tips. You have to work your way up to better shifts." The consensus explained by all servers interviewed is that the more seniority a server has, the better her shifts will be and the determining factor of which shift is better or worse, is the amount of tips to be earned. The statement from the server above demonstrates that despite a breakfast shift being during the day and meaning having a night off, servers consider night shifts to be more attractive because of higher sales and therefore higher tips and overall earnings. Four of the servers interviewed also identified a manager's preference in staff as a factor determining the schedule. These servers expressed that the manager's favourite staff are more likely to have the best shifts. One server explained that willingness to wear revealing clothing and personal appearance in terms of attractiveness was a known factor in impacting one's shift allocations at a particular restaurant in which she was employed. 
Several of the servers also discussed issues around booking time off and inconsistencies with the schedule. These respondents explained that their schedules were not consistent and to have the same shifts for two weeks in a row would be very unlikely. Half of the servers explained that they have worked for establishments where it is common practice to receive the weekly schedule on the Sunday night before the Monday for which the schedule was intended. One of the respondents explained that several of her employers would use the schedule as a punitive measure. Should a server perform a night shift poorly, she might be scheduled to work breakfast shifts or in extreme circumstances, completely wiped off of the schedule. Another server explained that a colleague had been taken entirely off of the schedule for one week as a punishment resulting from a disagreement between her boyfriend and the restaurant's manager. Overall the servers' responses indicated two significant elements to scheduling. All participants agreed on seniority as the predominant factor associated with the allocation of shifts. On the other hand, seniority will not promise a set schedule of the same shifts each week and is not impervious to scheduling as a mechanism of punishment or reprimand.

Much like the allocation of shifts in restaurants, all servers interviewed identified skill and seniority as leading factors in determining the allocation of sections ${ }^{13}$. One respondent explained, "I would work the same shift as a more senior server but they would make much more money because they had the better section." The amount of tables, amount of seats at the tables and popularity of certain areas will determine the

\footnotetext{
${ }^{13}$ The concept of sections refers to allocation of tables to a server. Each server is responsible for all guests who occupy these tables.
} 
sales of a server and therefore increase or decrease tip amounts. Another server described the allocation of sections based on the shift. She explained that the closing servers would get the best sections and be the most skilled on that shift. "As the other servers got cut $^{14}$, the sections expand so that eventually the closing server has the whole place." The overarching factor determinative of section allocation was described to be seniority and skill. Again, however, seniority and skill were not said to be invulnerable to outside factors. Three of the respondents explained that if a manager had a personal preference to working with you, your shift would more likely be a closing one. Another server explained that attractiveness would determine whether or not you could work on the 'bar side' of the restaurant.

While the data collected on allocation of shifts and sections is able to confirm and expand on research conducted by Von Massow and McAdams, indicating that these are major factors controlling tips (2012), question 11 seeks to determine which other factors contribute to tips earned by servers. More specifically the question asks servers to identify factors outside of their own control, which impact their likelihood of making higher or lower tips. Table 5 lists all factors mentioned by servers and the number of respondents that mentioned each factor.

The two most frequently mentioned factors include the shift and the section allocated during that shift. As a result of questions 6 and 8, which explicitly request participants to discuss scheduling and shift allocation, it is possible that these factors may have become overrepresented in their frequency during the interview process. It should also be noted that the frequency at which a factor was mentioned does not necessarily

\footnotetext{
14 Getting cut refers to the point at which a server is told to finish a shift.
} 
indicate the exact number of respondents who have experienced such a factor impacting the amount of tips earned. For example, only one server mentioned that the customer's level of consumption of alcohol can impact her tips. This does not mean that this is the only server interviewed who has experienced this factor in determining her tips, it only indicates that she is the sole respondent to have mentioned this example upon being asked. Further, the type of establishment is only mentioned by two servers yet is a factor which undoubtedly impacts all of them. The frequency of mentions for each factor may, however, indicate the consciousness of the servers to each factor in their current workplace.

\section{TABLE 5}

Factors Impacting Tips outside of Servers' Control

\begin{tabular}{|ll|}
\hline Factor & Number of Mentions (out of 10) \\
\hline Day and Time of Shift & 10 \\
Section & 10 \\
Clientele (income and behaviour of guests) & 8 \\
Kitchen Performance & 7 \\
Bar Performance & 6 \\
Personal Appearance/Attractiveness & 4 \\
Weather & 4 \\
Sports Games & 3 \\
Support Staff & 3 \\
Type of Establishment & 2 \\
\hline
\end{tabular}




\section{Events}

2

Consumption of alcohol by customer

The number of separate factors indicated by servers demonstrates that tips are inherently precarious and cannot be determined by providing excellent customer service. Of the twelve separate factors indicated, scheduling and sections will impact a server no matter the shift she works. Certain considerations such as a sporting event or an event at the establishment have the ability to dramatically increase the sales of servers. As one respondent explained, "I have never particularly cared for sports, but when hockey is on and I'm making way more money, I follow it like a fanatic." She went on to explain that the further a local team gets in any sort of playoff rounds impacts the amount of times that her workplace will see a high volume in customers, in sales, and by extension, in tips. Four of the respondents discussed the weather as an important factor. As many Ontario restaurants provide outdoor patio service, the servers scheduled for patio shifts rely on good weather conditions to be able to earn tips.

Many of the respondents discussed the demographics of the customers as relevant to tip earnings. More specifically, gender, age, and income of clients were listed as indicators that have an influence on tips. "A table of men is usually better than a table of women”, one server explained. Another elaborated on this notion, “... lonely, wealthy old men who want attention from younger underdressed girls". She went on to detail that this demographic would generally provide higher tips.

Related to the impact of clientele in influencing tips is the type of establishment in which the server is employed. Question 2 investigates the types of restaurants that 
respondents have worked in, providing the examples of pub-style, fine dining, sports bars and family oriented. All of the respondents indicated that they have been employed by all of the named establishments. Responses to question 11, around the impact of the type of restaurant on tip earnings, indicated that pub-style restaurants and sports bars render higher tip earnings due to the clientele, which the servers feel is more likely to be men. Finally, the majority of respondents discussed the performance of kitchen and support staff in impacting tips earned. The quality of the food and time that it takes to produce are both factors, which were identified as being likely to influence tipping practices. Table bussers can also influence a server's tips by being efficient at clearing tables and allowing new guests to be seated quickly, increasing sales and therefore tips. On the other hand, a slow busser who doesn't properly clean tables could lead to a decrease in tips. Hosts, who seat the tables, may also disrupt a server's income by seating more guests in one section than another. Bartenders were also identified as integral to the flow of service, as their ability to produce drinks quickly and efficiently is likely to impact wages for servers, much as the kitchen's production will. In the next section of this chapter, these influences on tips will be assessed as they relate to power and hierarchy in restaurants.

\subsection{Power and Control around Tips}

In section 4.1 the overall precarity of tips is established through an analysis of question 11, which addresses the many factors impacting the amount of tips earned by servers. This section elaborates on that analysis by providing an understanding of the structural industry standards that underlie this instability, as well as providing 
information about the mechanisms by which such standards are controlled within individual establishments, at the ground level. In order to provide a framework from which to understand the controls over tipping, I first explain the tip-out process ${ }^{17}$ through the experiences of the servers interviewed; next, I describe the controls that are established over tips more broadly; and finally I describe the equity of tip sharing, and reliability, and protections around tips.

Question 9 requests that respondents explain the tip-out processes of the restaurants industry as they have experienced them. All respondents began by explaining that the process varies based on the employer, however, none of the respondents had encountered a position in which tipping-out was not a requirement of the job. All establishments for which the respondents have been employed used a percentage system based on total sales in order to determine tip-out amounts per shift. The respondents named several other staff as recipients of these percentages of total sales. These include managers, kitchen staff, hosts, bussers, owners and dishwashers. The percentage allocated to each of the positions being tipped out varies based on the restaurant. The range of the tip out per position was between $0.5 \%$ to $2.5 \%$ of total sales. The highest named overall total tip-out for a particular establishment was $6 \%$. The lowest was $1.5 \%$.

The methods by which tip outs are dispersed to staff also varied greatly. Dependent on the establishment, servers would have direct amounts subtracted from the end of shift totals. This is exemplified by Appendix A, which illustrates the management and house (owner) tip outs being directly added to total sales and subtracted from tips

\footnotetext{
${ }^{17}$ This process refers to the distribution of a server's tips earned to other support staff working in the restaurant. Most commonly, the amount it based on a percentage of an individual server's total sales per shift.
} 
earned. The majority of servers experienced tip out standards which would have them remit a specific percentage of total sales to the employer to disperse to kitchen staff and management, while the percentages allocated to bussers, bartenders and hosts would be calculated by the server and handed to the specific support staff who is on the shift worked. Two of the respondents speculated that they did not believe management was remitting all of the tip outs to the staff appropriately. These servers believed that the employer would keep some of the funds for themselves before reallocating to the support staff. As one explained " The kitchen got paid an extra dollar an hour no matter what. The hostesses and bussers got the same. I'm pretty sure the management just pocketed the rest." While evidence of this process is anecdotal, it does indicate the lack of transparency in the tip-out process.

In discussions around tipping-out, respondents revealed other mechanisms by which tips are appropriated by employers. One respondent explained that her current employer implemented a cutlery cost payment. She explained that as a result of a shortage of cutlery, the owners began to add $\$ 3.00$ to the total amount owed back to the restaurant at the end of every server's shift. The servers were blamed for the shortage based on the kitchen manager's speculation that, upon clearing plates into the garbage, servers had been unintentionally dropping cutlery into it. No other staff was made to pay this cutlery cost. This ongoing payment by all servers was made for months and continues to be made. There is no transparency in the allocation of the money, which is taken to the actual purchase of cutlery.

One server recalled working for a restaurant, which would allow all staff to drink unlimited amounts of coffee and pop while on shift. Despite all of the staff being 
provided with these products, only the servers were made to provide compensation. Every two weeks, two dollars would be added to each server's cash owed at the end of the shift, and subtracted from total tip amounts. No opt-out option existed for those who chose not to consume these products.

Another trend, identified by six of the respondents, was walk-out fund payments. Much like the cutlery cost payments, this amount is not determined based on percentage of sales. Rather, it is a flat dollar amount added to the total funds owed by servers at the end of each shift. The range of money set aside for the walk-out funds ranged from $\$ 1.00$ and $\$ 2.00$ per shift. The justification for the walk-out fund, is to alleviate the costs of walk-outs for servers. The discussion around this fund revealed another industry standard by which tips are appropriated by employers. Should a table in a server's section leave the restaurant without payment for the meal or drinks served, certain establishments will impose this cost on the individual server. This imposition is facilitated by the inability of a server to void or remove the sales from the total amount owed at the end of a shift. Thus, the amount is added to the total owed back to the restaurant and subtracted from tips earned. The server must also tip-out based on this amount. One server interviewed explained that dependent on her managers interpretation of her efforts to prevent such theft, they may void the amount, not forcing her to take it from her tips, whereas if the manager believed insufficient efforts were made to avoid the theft by the customer, she would be made to pay the total amount of the walk-out.

While cutlery costs, walk-out funds, and beverage consumption costs were not named by all respondents, none of these topics were directly investigated in the interview process. The frequency of such practices can, therefore, not be determined. However 
this information does provide for meaningful analysis of the multiple ways in which tips can be appropriated and exploited from servers by employers as a result of structural industry standards.

When asked to determine specifically who has control over the factors (outside of customer service) influencing tips earned, all respondents named managers and owners. Most predominantly mentioned as the reason for this is the employer's ability to schedule shifts and sections for servers which determine the ability to increase scheduling. Although factors such as weather are out of the control of the scheduling manager, whether of not a server is placed on a patio shift can determine if she will work any hours that day. Similarly, the respondents explained that managers control the scheduling of shifts during popular sports events which will influence tips earned. Owners may exercise control over tips at more of a distance through the implementation of tip-outs for themselves and other staff. All of the support staff (kitchen staff, hosts, bussers, dishwashers, etc.) were named to have smaller influences and control around the ability of a server to earn tips through each of their job performances.

The issue of equity in tip sharing processes received a varying response. None of the servers outwardly opposed sharing the tips earned with other staff, however the majority did refer to circumstances of inequities in past experience. One of the concerns was that the support staff was paid different amounts through tip-out practices and that these amounts did not accurately reflect the work required for the positions. Other servers recalled shifts when the kitchen had made mistakes, which severely decreased the tip amounts earned. In these circumstances, the tip out to the kitchen remains the same. The consistent sentiment in explaining the issues with equity in tip out processes revolves 
around the precarity of the tips earned by servers and lack of control they can exercise over this, versus the consistency in tip out amounts for other staff. As an example, if a server were to sell $\$ 1000.00$ on a shift, they might be forced to tip out $5 \%$ or $\$ 50.00$ to support staff. Should the support staff perform poorly and significantly reduce the server's tips, they will still receive the $\$ 50.00$.

Despite the many factors rendering vulnerable the tips earned by servers, the majority of respondents believed there to be some reliability in tips earned. The wording of the question, however, allowed for varying responses and interpretations. As one server explained "I know that if I start my shift, I'll make at least $\$ 20.00$, which is reliably true.". Another interpreted reliability over time: “Some days aren't as good as others, but by the end of the week I usually make around the same amount.”. Others believed that tips are inherently unreliable and spoke of their own lack of control in terms of scheduling, weather and kitchen performance.

Finally, when asked whether they felt as though tips are being protected, none of the respondents agreed. One server recalled having been forced to claim $15 \%$ of sales as tip earnings by Revenue Canada despite not having made that much money in tips. This server also recalled being forced to pay for mistakes in punching in food orders and colleagues being forced to pay for dropped plates out of tips. Another respondent discussed not being able to start many of her shifts or being sent home early, resulting in making small amounts or no tips. The commonality expressed between all of these experiences is the power and control exercised by managers and owners over the tips earned by servers, despite the lack of stability or insurance by these authorities that the tips will, indeed be provided. 


\subsection{Gender}

In order to assess whether the precarity of tips is a matter disproportionately impacting women, questions 3 through 5 ask respondents to provide information regarding the gender roles of positions within the restaurants in which they have been employed. By investigating the gender roles in management positions, question 4 seeks to ascertain whether women's positions in more powerful roles in the restaurant industry reflects trends in broader society. This section will begin with an assessment of gender roles and positions in restaurants in order to provide context. Following this, responses to question 6, which deals more specifically with the reasons and experiences around such gender roles, will be provided.

When asked to explain the overall ratio of men to women in serving positions for the restaurants in which the respondents have worked, all servers expressed that more women had been employed in serving positions. Significantly, the range of experiences indicated the average disparity in gender for serving positions was 2 men serving for every 10 women. Eight of the respondents specifically indicated having been employed for restaurants, which only hire women to serve. Unlike serving positions, the respondents described a much less divisive pattern in managerial positions. While the majority or respondents have experienced a disproportionate amount of men in such roles, the overall range of disparity in gender for managerial positions was far less. For every 10 men in managerial positions, 3.7 women were represented. Table 6 , below, demonstrated the overall percentages of affirmative responses to such questions. 
TABLE 6

Results of Questions 3, 4 and 5 (on Gendered Positions in Restaurants)

\begin{tabular}{|l|c|}
\hline Experienced more women than men in serving positions & $100 \%$ \\
\hline Have worked in restaurants which only hire women to serve & $80 \%$ \\
\hline Experienced more men than women in management positions & $90 \%$ \\
\hline Have worked in restaurants which only hire men as management & $0 \%$ \\
\hline Believed gender to be a consideration in the hiring process of servers & $100 \%$ \\
\hline
\end{tabular}

In an assessment of the reasons for such a gendered disparity in serving positions, respondents were asked whether they believed gender to be a consideration in their hiring process. All respondents indicated that they did believe this to be a consideration. The reasons provided, however, vary based on individual experience. One server explained that her manager would take resumes from both genders, yet throw them away as soon as the males applicants would leave. Another respondent described a former employer who operated under the belief that "... women are meant to be waitresses and men are meant to be cooks, just like all cats are women and all dogs are male." In describing a different employer's beliefs, she explained, "It was more about attraction. The man should come and drink and the woman should serve him, like you're playing house and you should serve and clean up after him." All of the respondents indicated that the reasons they had been provided for gendered hiring processes within the industry revolved around the notion that women in serving positions would more likely attract men as clientele. Most graphically, one server recalled her experience being interviewed for a position serving in a pub. The manager explained to her that, "sex sells" as reasoning for only hiring 
attractive young women to waitress in his establishment. Several of the women interviewed supported this concept in explaining that the majority of servers with whom they had been employed were attractive, young and below a certain weight. Overall, the patterns of gendered segmentation of labour within the restaurant industry became quite overt through these questions and represent a strong correlation between the precarity of tips and gendered hiring practices.

\subsection{Chapter Conclusion}

This chapter outlines the data collected through the interview process and divides it into three analytical frameworks. First the precarity of serving work is established through investigations such as the duration of employment and stability of scheduling. Next the interplay of tips and stability of working conditions is established through information provided around tip-out processes and methods by which tips can be influenced. Finally, the gendered nature of serving is demonstrated by data provided around hiring practices and gendered tasks in the workplace. The data provided in the interview process strongly indicates that women are overrepresented in serving positions in Ontario. The workplace for these women is marked by precarity and gender based discriminatory practices. 


\section{Chapter: Interpretation of Data}

\subsection{Restaurants within broader Gendered Employment Trends of Precarity}

In order to meaningfully contextualize the data provided through the interview process, this section will interpret such information within the context of literature provided in the third chapter, on the broader regimes of gendered and precarious employment trends in Canada. In order to encompass the large range of factors impacting precarity in labour (Vosko, 2005), the precariousness of serving in restaurants is assessed both through established industry standards and through the less formalized norms around tipping regimes. Industry wide precarity is measured through stability of employment, wages, benefits and hours of employment (full-time or part-time work). The investigation into the instability of tips earned by servers begins through an analysis of the factors established by Von Massow and McAdams (2012) of scheduling and sections and is largely expanded on by exploring various other factors identified in the interview process, which act to increase the precarity of tips for servers.

The history of women's work in Canada reveals deeply rooted patriarchal beliefs underlying divisions of labour (Kessler-Harris, 1988). Much as former employment legislation dictated women's minimum wages to be less than for men, under the assumption that such wages exist only to supplement that of the male bread-winner (Vosko, 2001), contemporary minimum wages for the serving industry, represented predominantly by women (Statistics Canada, 2006), are legislated substantially below the otherwise mandated minimum wage. Despite overtly sexist legislative standards such as the women's minimum wage, having been abolished, patriarchal oppression remains intact through such contemporary standards. 
Through an analysis of the data provided on industry standards, it is clear that women working in restaurants are subjected to the unstable and exploitative standards of the secondary labour market. Much as women have been, and continue to be, overrepresented in feminized occupations such as clerical work, nursing and sales work, interview data supports the claim that women are consistently overrepresented within the occupation of serving in Ontario. All respondents expressed having worked with serving colleagues who were predominantly women. Moreover, the responses provided explicitly describe large numbers of establishments, which will only hire women as servers. Following trends in occupational distribution, which have seen an increased amount of women entering the primary labour market (Statistics Canada, 2010), interview data demonstrates a far less divisive role of men and women in managerial positions within restaurants. These numbers coincide with an analysis of gendered labour, which encompasses the divisions in class and labour markets.

Of the servers interviewed, only one had been placed in a managerial position despite the majority of respondents having been employed in the industry for several years. It is noteworthy that the respondent who was employed as a manager was also expected to perform her duties as a server while managing shifts. An analysis of class might suggest that while more affluent women have become increasingly involved in the primary labour market, following paid education, women who have historically experienced disadvantage continue to be overrepresented in the feminized and more unstable working conditions of the secondary labour market. This also raises concerns around the subtle mechanisms by which patriarchy can be perpetuated in contemporary labour markets. 
The precariousness of industry-wide standards for servers was established through the analysis of multiple factors in the interview process. The overall instability of serving positions within restaurants in Ontario was revealed to be a matter of concern on multiple levels. Firstly, the number of restaurants in which each respondent had been employed vastly outnumbered the average number of years for which the servers had been employed in the serving industry. On average, the respondents had been employed as servers by 11 restaurants, the highest number of employers being 17 . This indicates that there is a high rate of movement from one establishment to the next, making long-term employment for a single employer rare in the serving industry.

Precarity for serving positions was also indicated by both the lack of long term full-time work and the conceptualizations of full-time employment articulated by respondents. While all of the respondents did believe that they had been employed on a full-time basis, the average longevity of such full-time employment for one employer was two years. Again, this marks the overall instability of long term employment for one employer. In describing the actual experience of working full-time in a restaurant, the servers explained that the actual hours per week often did not amount to 35 , which is the legal definition of a full-time work week under the ESA.

Common practice in scheduling for servers in restaurants was explained to involve a shift starting time which may vary based on the volume of customers in the restaurant. Should the night be slower than the scheduling manager had anticipated, servers may not begin the scheduled shift, dependent on the practices of the particular establishment. All of the servers explained that end times for shifts were not provided through scheduling, and also were largely dependent on the volume of guests. As such, 
servers are expected to go into each shift scheduled without any knowledge of how long the shift might be (one respondent explained that her shift may range from 3 to 12 hours long). Further, servers may not even begin their shifts should the night be slower than anticipated, or if the scheduled shift is on the patio and the weather is unpleasant. None of the servers had been financially compensated for cancelled shifts by an employer. The overall uncertainty in scheduling in the serving industry exemplifies the precariousness of such gendered employment. Further the resulting misconceptualization of full-time work illustrates that the standards and expectations of women serving in Ontario have become significantly lowered far below what is legally defined.

Another significant marker of the precarity of serving is the lack of benefits provided to serving staff in Ontario. Of all the respondents, only one had received a benefits package from her employer. These benefits, however, were dependent upon her working both the position of server and manager at the same time. As such, the benefits would not have been available to her as a server alone, indicating that none of the respondents had received benefits from an employer for working in a serving position.

Further troubling the compensatory issues for servers is the legally mandated minimum wage which only applies to serving staff who provide alcoholic beverages. None of the respondents had been paid more than the servers' minimum wage for a waitressing position, despite one having been employed at the same establishment for just over 3 years. It was established through the interview process that seniority in a serving position is generally rewarded by the scheduling of shifts, which are known to render higher tips, rather than providing increased wages, which could be stable and predetermined. 
This mechanism of promotion and demotion through scheduling is problematic for various reasons. Some of the servers interviewed had experienced workplaces which would provide better shifts to more attractive servers, overlooking the unspoken norm of providing such shifts to more experienced servers. Four of the respondents explained that earning good shifts entails being experienced, as well as remaining on the good side of management. One server described a workplace where the manager's preferred staff, who would stay and have drinks with him after work, would be scheduled the best shifts. Another explained that a server's willingness to wear revealing clothing to work would earn her better shifts on busy bar nights. Thus, servers who rely on a strong work ethic and experience within an establishment in order to receive promotions through scheduling remain vulnerable to uncontrollable factors such as these.

The ESAs hands-off approach of regulating tips facilitates the ability of restaurant managers to provide promotions and demotions based on considerations which many respondents identified as related to gendered and sexualized workplace expectations. For one server, her shifts on Friday and Saturday nights would usually yield between $\$ 200.00$ to $\$ 300.00$. As a result of refusing to wear the restaurant's newly implemented and more revealing uniform, she was told that it would no longer be appropriate to give her night shifts. This change in scheduling resulted in weekday shifts which yielded roughly $\$ 50.00$ in tips. Thus her pay was reduced by more than half as a direct result in her decision to refuse the sexually exploitative uniforms. Since the ESA does not provide protections for tips, and hours of work per shifts had remained the same, no legal protection was made available and she sought new employment. Circumstances such as this exemplify and support Von Massow and McAdams' research (2012) indicating that 
management may exert control over a server's ability to earn tips, while also adding an important layer to this issue around power and gender. On a smaller scale, in terms of financial implication, managerial controls over sections assigned to servers became a prevalent concern raised in the interview process. These concepts will be elaborated on in the preceding section on gender roles and masculine hegemony.

While Von Massow and McAdams provide important data around the managerial controls exerted over sections and scheduling impacting tips as wages for servers, many additional factors were identified by respondents of this study. Although many of these factors can be linked to scheduling, they provide for a valuable understanding of the additional layers of precarity involved in serving work. Table 5 lists the various elements named by respondents as having impacts on tip earnings. These factors can be divided into sub-categories of those which are related to scheduling, those which are influenced by other staff working in restaurants and those which depend on the characteristics of the establishment.

The efficiency of bartenders, kitchen staff, bussers and hosts were all named to have an impact of the ability of servers to earn tips. Each of these support staff plays an integral role in providing the customers with a service for which servers are paid or not paid for through tips. Despite the precarity and subjective nature of tips being provided by customers, serving staff are required to provide tip-out amounts based on total sales. Thus, while the performance of all support staff within an establishment is rewarded with a steady and reliable percentage of tips based on sales, a server's earnings through tips are not. Many of the servers interviewed expressed concerns with this process and explained situations in which their earnings were deeply impacted by the performance of 
support staff. Further, such relations amount to a power dynamic, which places servers in positions which must depend upon positive relations with many coworkers which might be out of their control. For instance, one respondent explained that her negative rapport with kitchen staff had led to her orders taking longer to be made, leading customers to tip less. This dynamic is relevant for all relations between servers and colleagues who provide the support necessary to provide positive customer relations. Dependent on tipout amounts, servers may actually be forced to pay support staff for services, which are not rendered and actually lose income as a result of such processes. Von Massow and McAdams investigate the implications for restaurant owners around tip-out procedures and equity, but they do not discuss the possibility of serving staff leaving shifts with no tips, as identified in my interview process.

Factors that influence scheduling include, weather, sports events, and restaurant events. All of these elements will impact the volume of customers attending restaurants and bars on specific shifts, thus impacting a server's ability to produce tips. Some establishments may host large parties for events, provide sports events on televisions or have patios, which are only open based on agreeable weather, largely impacting the volume of customers. These scheduling implications should be understood as an additional layer of precarity added to the inherent inconsistency of tip earning based on busier days and times of the week.

The final section of factors identified by servers as impacting tips as wages, are those which are more specific to the establishment in which servers are employed. These were identified by respondents to be clientele, style of establishment, and personal attractiveness. Many of the servers interviewed described multiple sorts of restaurant 
working experiences in bars, pubs, fine dining, family restaurants, etc. Two of the respondents explicitly named pubs and bars as the best tip earning establishments to be employed for. This is linked to their conception that these places are more likely to have male patrons, which were described to be the best tippers, particularly for young attractive women. Personal appearance/attractiveness was identified by four respondents to be integral to tip-earning. Clearly, such a factor is quite uncontrollable for women in the industry and subject to interpretation by the consumers of her services.

As Vosko (2006) argues, an analysis of precarious employment must understand the multi-faceted and layered dimensions of precarity. While many broad industry-wide quantitative analyses of precarious work in Canada exist, it is important that these studies are grounded in case studies which reveal the more personalized and specific nature of the impacts of precarious employment. The various unwritten industry standards and protocols around serving work reveal massive vulnerability in terms of stability of work, longevity of employment and social benefits. More specifically, the investigations into tips expose a vast realm of subjective factors destabilizing the stability of tip earnings. Supporting much of the research produced on precarious labour and gender, it is clear that this case study on women serving in Ontario (Bernstein et al, 2005; Fudge \& Vosko, 2001 ) is exemplary of the gendered nature of precarious employment and inadequate protections available to them. 


\subsection{Gender Roles in Restaurants and Masculine Hegemony}

As discussed in section 2.1, my methodological approach to understanding gender roles and the social reproduction of them in restaurants is through the theoretical lens of hegemonic masculinity. In taking this approach, I engage with two interconnected levels analysis. Firstly, in order to provide insights towards the context of gendered subordination, I evaluate the restaurant industry in terms of its structural procedures and barriers for women. This will be elaborated to include an analysis of the role in tips in facilitating such industry wide gendered hierarchies. This analysis is extended to the broader regimes of gendered labour segmentation and the controlling forces around labour markets. Secondly, in section 5.3, I assess gendered subordination through juridical force in terms of employment legislation and more specifically, the Ontario Employment Standards Act. Assessment of the ESA as rights based legislation, through the lens of hegemony and counter-hegemony, is also undertaken in order to evaluate its ability to create equity in the workplace and labour market.

It has been well established by many social science and occupational researchers that serving tables in Western society is an occupation predominantly undertaken by women (Creighton, 1982; Hall, 1993; Williams, 1994; Ramusson, 2011). This case study supports those findings in the context of contemporary Ontario restaurant workplaces. Each of the interviewees affirmed that women dominate the serving staff of all establishments in which they have been employed. Further, many of the respondents describe having been employed for restaurants that will only hire women to serve. Finally, all respondents believe that gender did play a central and affirmative role in being hired within restaurants. Most notably, one respondent described her manager 
explaining that "Sex sells" and therefore only women would be hired in serving positions at his establishment. The processes by which servers are subordinated based on gender in restaurants can be understood as operating under the broad scope of a patriarchal society, but will also be broken into two separate categories of workplace oppression in order to analyze the role of hegemonic masculinity in restaurants. These include relations with customers and inter-workplace relations.

Ninety percent of respondents noted that men are more likely to be in managerial positions in restaurants. The same can be said of men working in kitchens and bussing tables. The roles performed in these positions entail a gendered division of labour that sees serving as a feminine role, marked by its subordinate features to both customers and other staff, and managerial positions and kitchen work as requiring more intelligence and skill. As it is predominantly men who conduct hiring for restaurants it is through means of male hegemonic control that women continue to be placed in serving positions rather than men. Despite increased numbers of women in management, it should be noted that this disproportionate hiring of women for serving positions remains. As such, an analysis of the reproduction of serving tables as women's work should be understood within broader patriarchal norms of society, which induce more women to apply for such positions and more managers to feel compelled to hire women. Industry standards have become such that restaurants compete based on the consumption of food and liquor, but also on the consumption of gendered service work. As such the servers themselves become commodified, often on the basis of attractiveness. One respondent explained, after a chain-restaurant known for employing young, attractive women opened up next door to the pub she was employed for, her management introduced a new, more 
revealing, dress code and only hired women to serve in order to compete financially. This example and the systemic hiring of women into subordinate serving positions are able to demonstrate the practical means by which the ideological gender roles of women are reproduced in Ontario restaurants. By predominantly positioning women working for restaurants as servers, the inner relations of the workplace that are divisive based on jobtype also become divisive based on gender.

Outside of the hiring structures, which act to reify gender roles in restaurants (Neumark et. al., 1996; Lerum, 2004), exists a hierarchy within the workplace, which operates to systemically socially disadvantage women in serving positions. Although tips are able to provide servers with what may be a much higher income than other workers, for example kitchen staff, it is the precarity of these tips which places serving staff in more subordinated social roles in restaurants. The previous section of this chapter focused on the factors, which are known to increase the precarity of tips. In this section, the controls of management and other staff will be assessed in influencing such vulnerabilities, with specific attention paid to the gendered nature of these roles.

Von Massow and McAdams describe the two-tiered system of restaurants as they operate on the basis of a "front of house" and "back of house" staffing relationship (Von Massow \& McAdams, 2012). The front refers to all of the staff whose jobs predominantly take place in customer relations. These include servers, hosts, bartenders, managers and bussers. The back refers to line cooks, prep cooks, dishwashers and, depending on the specific establishment, the bussers will also be considered back of house. The back of house is commonly entirely made up of men, whereas the front of house sees a slightly more diverse gender representation overall. However, as discussed, 
serving staff are overwhelmingly represented by women. The gendered division of labour in restaurants provides for mechanisms by which to establish differential expectations and levels of subordination. Examples of this are demonstrated by the revealing uniforms many servers described being forced to wear versus the kitchen staff whose physical attractiveness and compliance in revealing uniform standards is not a job requisite. In objectifying women based on appearance, the restaurant as a workplace, acts to reinforce the social ideological norms that devalue a woman's capacity to perform labour. It is in this way that the social reproduction of what is considered feminine, in terms of sexuality, is reproduced in restaurants. In considering the actual tasks associated with serving, such as acting pleasant, cleaning up after patrons and providing meals, it becomes evident that the social reproduction of the role of women in family life and under that male bread winner model is also reproduced in the role as server.

One of the additional mechanisms by which the subordination of women in serving positions is facilitated within restaurants is through tipping structure. All servers interviewed described the roles of other staff in impacting their tip-earnings. The reliance that is created through this structure produces a working relationship in which servers must appease other staff in order to most efficiently generate tip-wages. Should a waitress upset a cook or busser, he might delay her food orders or avoid cleaning her section of tables. In turn, this waitress will produce less efficient table service, seeing fewer customers and sales from which to generate tips, or lowered individual tips. While performing the gendered role of table serving (Hall, 1993), waitresses must also navigate relations with support staff in order to secure these wages. In this way, servers are subordinated to the men cooking and bussing tables. Thus hegemonic masculinity is 
embedded in the structural nature of serving work through the ability of support staff to impact tip-wages. It should also be noted that all support staff, inclusive of bartenders, hosts and managers, will impact the tips generated by servers. However, despite these staff not being largely overrepresented in terms of gender, their influence on servers, who are overrepresented by women, still maintains and supports the gendered subordination of women, which acts to reinforce masculine hegemony.

The inequity of the process by which servers become reliant on positive relations with all other restaurant staff is further exacerbated by the tip-out structures inherent to the majority of Ontario establishments. As a result of providing percentages of total sales to each of the other groups of staff members, servers remain the sole workers in restaurants who do not receive a set amount of tips based on the restaurant's sales. Instead, servers are forced to distribute their own precarious tips to all support staff in stable amounts. In considering that serving is the sole position in restaurants, which is grossly overrepresented by women and is also the sole position which is marked by severely unstable wages, it is clear that workplace wage insecurity in restaurants is a problem disproportionately impacting women. It is through this insecurity that masculine interests can be exercised by threat of coercion. The ability the majority of other staff to impact wages for women in serving positions creates an atmosphere in which servers are first encourages to consent to performing gender roles and remaining subordinate, however are ultimately operating under the constant threat of coercion. This relationship between staff very clearly exemplified Connell's conceptualization of gender roles in the workplace (2005). 
The instability of tips can also been seen through the scheduling practices which see servers becoming reliant on good shifts and sections (as conceptualized in section 4.1). The informal and subjective processes by which sections and shifts are allocated result in a power dynamic, which sees the server as continuously becoming vulnerable to the will of management. This allows for a multitude of exploitative and gender based norms to develop and become reaffirmed. One example identified in the interview process included the need for servers to maintain a friendly and even flirtatious relationship with men in management in order to secure good tip earning shifts. Servers who stayed after work to have drinks with managers would receive priority scheduling, as opposed to those who did not. Similarly, these servers would be given better closing sections, again yielding higher tip earnings. As a result of no legislated repercussions for the subjective scheduling of serving staff, despite the massive impact that this has on tips as wages, servers feel obligated to participate in social relations with male management in order to receive better shifts and higher wages. Thus servers are compelled to consent to the hegemonic controls of men in power of scheduling in restaurants as a result of the constant threat of coercion.

As a result of such processes, many gendered and exploitative measures are made possible in restaurants, which are largely not seen in many other contemporary workplaces. Another example discussed in the interview process involves a server who was requested to wear more revealing clothing to her shifts. Management explicitly told her that failure to do so would result in day shifts (as opposed to her regular night shifts), significantly decreasing her tip earnings. Other examples include servers being scheduled sections based on personal attractiveness. Again, the lack of legislative 
controls around tipping creates a dynamic where alternatives to such practices are inaccessible, thus facilitate an acquiescence of serving staff to such norms.

Finally, serving staff become subordinated and exploited by patrons of such establishments as a result of the precarity of tips. Many of the respondents discussed earning higher tips from wealthy older men, who want young attractive women to serve them. The demeanour and attractiveness of the women serving under these circumstances must then be altered to reflect perceived consumer needs. While the research questions established in this study do not assess these relations in detail, many of the servers discussed the need to appear attractive and put on a submissive act when serving tables. Further, many described situations which, in most other professions, would not be tolerated behaviours on the part of patrons. However, servers accept them as a necessary part of work. The perceived need to consent to such workplace relations is facilitated through both the perceived risks around receiving bad shifts and the need to appease the patrons in order to attain high tip earnings.

In this analysis of restaurant industry structuring, it is clear that servers become consenting parties to their own subordination both through processes of consent and coercion. The servers feel that it is in their best interest to wear provocative clothing and act with a flirtatious demeanour in order to gain better tips and tip earning shifts. In the event that they do not consent to these practices, managers and owners of restaurants are able to assert a sort of force through withholding the ability of the servers to make good tips. Customers are also in a power position over servers, influencing income and thus asserting dominance. It is through such mechanisms that hegemonic masculinity is reified and the social reproduction of gender roles is reproduced in restaurants. 
This analysis of Ontario restaurants demonstrates that much of the research around gender segmentation in the labour market is being replicated in contemporary workplace segmentation as well. Much as entire industries associated with social reproduction are ideologically perceived of as women's work, specific roles within workplaces have also become feminized in this way. Through the preceding literature review on topics of gendered labour segmentation and sexualized and gendered roles in restaurants, it is evidenced that the social reproduction of unequal positions is taking place in a hegemonic capitalist order. This is occurring in two interconnected mediums. First, women are being systemically marginalized into precarious working conditions. This marginalization is able to sustain the ideological role of women as caregivers, educators and homemakers. Secondly, the gendered nature of serving tables acts to reify a social construction of femininity under the gaze of hegemonic masculinity. The result

of these processes is a continuing social order in which women are sexualized and placed into unequal workplace opportunities, under the threat of coercive measures that may be used to reinforce the ideological position of hegemonic masculinity.

In the following section, an analysis of the Employment Standards Act will take place, with respect to the juridical coercive force resulting from the legislative omission of tips, as well as its ability to create rights-based positive change through amending the definition of tips as wages and other amendments being proposed at the Ontario Legislature.

\subsection{Legislative Problems and Solutions around Contemporary Tipping Practices}

In this section the broader legislative factors impacting tipping and equity in service work will be explored in the context of the Ontario Employment Standards Act. 
By assessing the Act's role in conjunction with a conceptual analysis of hegemony and the law, it can be understood that emancipation from the reproduction of the gendered segmentation of labour will likely not be accomplished solely through amending such legislation. Rather, the current ESA legislation around tips and wages will be understood as a tool that facilitates such inequities. Possible amendments and reforms and their potential to mitigate negative and gendered implications for servers are assessed under the scope of hegemonic masculinity.

As established in section 2.2, the Ontario Employment Standards Act is problematic for serving women in Ontario in two central capacities. First, the Act's Regulations provide that alcohol serving staff for restaurants may be paid a minimum wage below that of any other worker in Ontario. This is premised on the belief that such wages will be supplemented by tips. Second, the Act specifically exempts tips from the definition of wages, thereby absolving government from any responsibility to protect these assumed wages. As outlined in section 3.2, NDP representative, Michael Prue, after receiving many complaints from constituents around tipping structures in local restaurants, has attempted, on several occasions, to provide meaningful intervention. Originally presented as Bill 114, An Act to Amend the Employment Standards Act, 2000 with respect to tips and other gratuities, the amendment would simply state, "An employer shall not take any portion of an employee's tips or other gratuities" (Appendix B.1). While many employers in Ontario are known to withhold tips from servers in order to supplement their own incomes, this Bill does not encompass the wide range of problematic outcomes, which are developed by contemporary tipping models, as seen in chapter four. For example, servers providing tip earnings to supplement the income of 
other staff would remain commonplace, and the subordinate roles of servers in the hierarchy of restaurants would thus remain the same.

Despite Prue's bill not being controversial in nature, as it is difficult to argue that employers should maintain rights to withhold servers' tips, many business associations did speak against the bill in the legislature. The several attempts to have this legislation enacted demonstrate the inefficacy of legislative reforms to adequately protect workers. In the most recent (and still failed) attempt to pass the amendments, they were quite significantly modified to provide more detail and security around the bill's protections (Appendix B.2). These changes, however also provided exemptions, allowing restaurant owners to withhold tips on the basis of their own involvement in the business affairs.

The difficulty with accepting either the original or amended legislative reforms is that both do not adequately address the legislative failures of the ESA in protecting servers. Meaningful ESA reform must abolish the current standards by which servers are not afforded the same protections over tips, which all other working members of Ontario are able to enjoy. By defining tips as separate and apart from wages, the ESA underprivileges income that it assumes servers are receiving. Additionally, the lesser minimum wage for servers creates a deeper reliance on these gratuities. In order to meaningfully remedy the many inequities resulting from current employment standards in Ontario (as exemplified in chapter four), this hands off approach to the regulation of tips must be stopped. Rather than specifically exempting an occupation, whose vast majority of members are women, from protections under the law, we must offer the same, if not more protection to this vulnerable population of precarious workers. There are several means, by which this might be achieved, inclusive of both legal and industry reforms. 
The ESA must remove its exemption of tips from the definition of wages in order to provide the same, if not similar protections to servers. While the earning of tips is an unstable practice which might not be easily governed by the Ministry of Labour, the protections around the tips once they have been provided from customers to servers must be equal to those which are provided to all other workers in Ontario, in order to mitigate the inequities faced by women in serving professions. By providing legal sanctions to prevent managerial staff and employers from exercising controls over tips as wages in subjective and potentially sexist way, the ESA would better represent the needs of servers in the workplace.

While these recommended amendments to the ESA and oversight by the Ministry of Labour have the capacity to alleviate the precarity of tips as wages for servers, there are many other factors which act to facilitate inequities in serving positions that exist outside of the law and within the ideological frame of hegemonic masculinity and social reproduction. As Hunt explains, hegemonic control is often premised on a minimum standard of acceptable life, accompanied by a compromise in the interests of the subordinate group, protecting that standard (1990). Employment legislation in Ontario can be thought of as reinforcing the minimum standards as well as providing minimal protections for them. As such, the emancipatory powers of the ESA to impact the overall working conditions of women in restaurants, must be understood as simultaneously reifying the subordinate position of women working in restaurants. This may also be linked to the overrepresentation of feminized industries more broadly in their governance by the ESA rather than labour legislation and collective bargaining rights. 
Although, in a broad sense, the ESA can be understood as a tool in the social reproduction of hegemonic masculinity and subordinated segmented feminized work industries, its ability to be used as a tool towards counter-hegemony must also be considered. As a rights-based legislation, the ESA has the capacity to reinforce counterhegemonic strategies as well (Hunt, 1990). So, while the ESA is currently being applied as a tool that created precarity in wages for women in restaurants, this has the potential to change. This change, however, must take the form of a much broader social understanding. In order to create more equitable working relationships for women in restaurants, the broader social ideological understandings around gender segmentation in the labour market and in workplaces must be challenged.

\subsection{Chapter Conclusion}

In this chapter data collected through the interview process is applied to trends in women's employment in Canada. These trends are marked by precarious and unstable working conditions, which are exemplified within Ontario restaurants for women. The case study is then placed within the framework of hegemonic masculinity, revealing the exploitative measures by which such understandings are perpetuated in restaurants.

Finally, the employment standards which govern such gendered and precarious employment relations are examines using an understanding of rights based legislation and hegemony. The main themes that can be taken from this chapter are those of masculine hegemony on a macro level, as within industry standards and rights based legislation being exemplified on the micro level, within Ontario based restaurant workplaces. 


\section{Chapter: Conclusion}

This thesis research has sought to investigate the inequities in tipping structures in Ontario based restaurants for women. More specifically, the goal of this thesis is to answer: How does ESA legislation around gratuities and tipping impact equity in standards of employment for women serving liquor in Ontario? And what reform would be adequate in resolving exploitative practices that result from tipping regimes? Through interviews with servers in Ontario restaurants, a conceptual understanding of the real implication of the Act's role in creating in workplace inequity has been developed. These inequities are situated within broader understanding of hegemonic masculinity in contemporary Canadian culture, which underlies ideological norms around gender and work. Throughout this thesis, the segmentation of women into severing positions is restaurants is revealed to demonstrate a pattern that is reflective of the segmentation of women in the labour markets in Canada.

Although the central questions that this thesis posits at the start revolve around legislative reform, the theoretical framework around hegemonic capitalist order are able to reveal that a much more complex remedy is in order, if we hope to see meaningful social change. While amendments to the Employment Standards Act are required to help alleviate the subordination and unfair treatment of women in restaurants, the roots causes of such problems span much further than legal understandings. Masculine hegemony is present in many facets of everyday life and is exacerbated by gendered workplaces and legislative standards, but cannot be ended through these mechanisms alone. Rather, a meaningful solution to the subordination and gendered exploitation of women in restaurants must occur through legal and social change. 
In terms of practical policy reforms that might mitigate the unequal and gendered divisions of labour and subordination in Ontario restaurants, the Employment Standards Act must be amended more directly than the bills that have been proposed to date in the Ontario Legislature (See Appendices A and B). Rather than focusing on the direct theft of tips by managers and owners, the myriad ways by which tips are subtly distributed and influenced by managing parties in restaurants must be considered. In order for the ESA to provide meaningful and adequate protection to servers, it must remove the explicit omission of tips from its definition of wages. By doing so, a more holistic approach to employment protections will take place, rather than a band aide solution to this legislative gap. This amendment would see a wider range of protections provided to servers, removing their employment from a subset that is below the average standards of minimum protections. Still, it must be acknowledged that while the precarious nature of the serving industry is dominantly facilitated by corrupted tipping regimes and lack of legislative oversight, many broader social factors act to reaffirm this precarity.

Building on literature around gender based exploitation within restaurants and tipping patterns, this thesis has developed an understanding of industry wide internal practices of gendered exploitation through tipping structures. Despite its acknowledgement of gendered exploitative inequities that exist within the dimensions of servers and clients, such areas have not been explicitly investigated. An extension of this research might include an analysis of the mechanisms by which tipping is used to subordinate women in serving positions to masculine hegemony in terms of customer/server relations. Concerns around this particular issue were proposed during the interview process. Another area of research that would benefit the working 
conditions of servers in Ontario based restaurants might include in investigation into the complaints process that takes place once a concern in raised to the Ontario Labour Relations Board. Some of the interviewees did mention colleagues to have encountered negative and unresolved experiences with such processes. Finally, the competing legislative understandings of the ESA, which preclude tips from the definition of wages versus recent crack-downs under federal taxation legislation, which conceive of tips as taxable income, might be further investigated to reveal a discrepancy in the two legislative regimes.

This thesis research is able to conclusively provide a meaningful case study of Ontario based restaurants that reveals the gendered segmentation of labour and sexualized exploitation of women through ongoing tipping structures that are systemically facilitated by the Ontario Employment Standards Act. These problematic and inequitable relations may be mitigated by reforms to the ESA, however an understanding of masculine hegemony through tipping processes in restaurants in Ontario reveals that meaningful change to these working conditions for women in the serving industry must take place within both legislative bodies and social understandings. Thus, while the above ESA reforms are recommended, it is integral that they come in connection with critical understandings of hegemonic masculinity in our society. 


\section{Appendices}

\section{Appendix A}

Example of Tip-Out Deductions on Server Sales Read

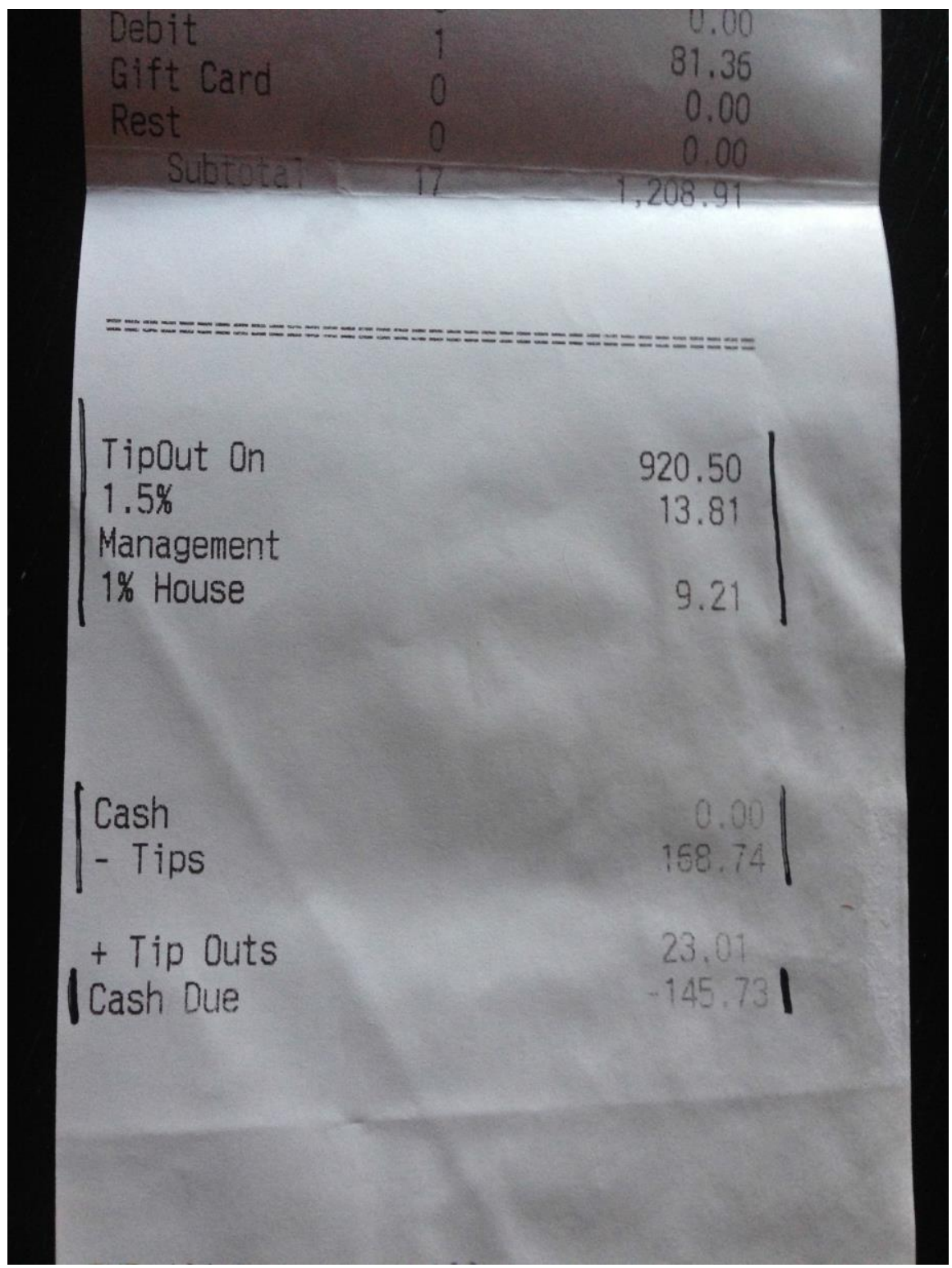


Appendix B

Bill 49: An Act to amend the Employment Standards Act, 2000 with respect to tips and other gratuities

B.1 Bill 49 Original

Bill 49

2013

An Act to amend the Employment Standards Act, 2000 with respect to tips and other gratuities

Her Majesty, by and with the advice and consent of the Legislative Assembly of the Province of Ontario, enacts as follows:

1. The Employment Standards Act, 2000 is amended by adding the following Part:

\section{PART V.1TIPS AND OTHER GRATUITIES}

Tips and other gratuities

14.1 An employer shall not take any portion of an employee's tips or other gratuities.

2. This Act comes into force on the day it receives Royal Assent.

Commencement

Short title

3. The short title of this Act is the Protecting Employees' Tips Act, 2013. 
B.2 Bill 49 as Amended

Bill 49

2013

An Act to amend the Employment Standards Act, 2000 with respect to tips and other gratuities

Her Majesty, by and with the advice and consent of the Legislative Assembly of the Province of Ontario, enacts as follows:

1. The Employment Standards Act, 2000 is amended by adding the following Part:

\section{PART V.1TIPS ANDOTHER GRATUITIES}

Tips and other gratuities

14.1 An employer shall not take any portion of an employee's tips or other gratuities.

\section{PART V.1EMPLOYEE TIPS AND OTHER GRATUITIES}

Employee tips and other gratuities

Definition

14.1 (1) Subject to subsection (2), in this Part, "tip or other gratuity" means,

(a) a payment voluntarily made to or left for an employee by a customer of the employee's employer in such circumstances that a reasonable person would be likely to infer that the customer 
intended or assumed that the payment would be kept by the employee or shared by the employee with other employees,

(b) a payment voluntarily made to an employer by a customer in such circumstances that a reasonable person would be likely to infer that the customer intended or assumed that the payment would be redistributed to an employee or employees,

(c) a payment of a service charge or similar charge imposed by an employer on a customer in such circumstances that a reasonable person would be likely to infer that the customer assumed that the payment would be redistributed to an employee or employees, and

(d) such other payments as may be prescribed.

\section{Same}

(2) "Tip or other gratuity" does not include such payments as may be prescribed.

\section{Prohibition re tips or other gratuities}

(3) An employer shall not withhold tips or other gratuities from an employee, make a deduction from an employee's tips or other gratuities or cause the employee to return or give his or her tips or other gratuities to the employer unless authorized to do so under this section. 


\section{Statute or court order}

(4) An employer may withhold or make a deduction from an employee's tips or other gratuities or cause the employee to return or give them to the employer if a statute of Ontario or Canada or a court order authorizes it.

\section{Exception}

(5) Subsection (4) does not apply if the statute or order requires the employer to remit the withheld, deducted, returned or given tips or other gratuities to a third person and the employer fails to do so.

\section{Pooling of tips or other gratuities}

(6) An employer may withhold or make a deduction from an employee's tips or other gratuities or cause the employee to return or give them to the employer if the employer collects and redistributes tips or other gratuities among some or all of the employer's employees.

\section{Same - employee representative}

(6.1) If an employer collects and redistributes tips or other gratuities under subsection (6), an employee representative chosen by the employees of the employer shall be present for and shall participate in the collection and redistribution.

\section{Same - exception}

(6.2) An employer shall not redistribute tips or other gratuities under subsection (6) to such employees as may be prescribed. 


\section{Employer etc. not to share in tips or other gratuities}

(7) Subject to subsections (8) and (9), an employer or a director or shareholder of an employer may not share in tips or other gratuities redistributed under subsection (6).

\section{Exception - sole proprietor, partner}

(8) An employer who is a sole proprietor or a partner in a partnership may share in tips or other gratuities redistributed under subsection (6) if he or she regularly performs to a substantial degree the same work performed by,

(a) some or all of the employees who share in the redistribution;

or

(b) employees of other employers in the same industry who commonly receive or share tips or other gratuities.

\section{Same - director, shareholder}

(9) A director or shareholder of an employer may share in tips or other gratuities redistributed under subsection (6) if he or she regularly performs to a substantial degree the same work performed by,

(a) some or all of the employees who share in the redistribution;

or

(b) employees of other employers in the same industry who 
commonly receive or share tips or other gratuities.

Transition - collective agreements

(10) If a collective agreement that is in effect on the day section 1 of the Protecting Employees' Tips Act, 2013 comes into force contains a provision that addresses the treatment of employee tips or other gratuities and there is a conflict between the provision of the collective agreement and this section, the provision of the collective agreement prevails.

\section{Same - expiry of agreement}

(11) Following the expiry of a collective agreement described in subsection (10), if the provision that addresses the treatment of employee tips or other gratuities remains in effect, that subsection continues to apply to that provision, with necessary modifications, until a new or renewal agreement comes into effect.

Same - renewed or new agreement

(12) Subsection (10) does not apply to a collective agreement that is made or renewed on or after the day section 1 of the Protecting Employees' Tips Act, 2013 comes into force.

\section{Enforcement}

(13) If an employer contravenes subsection (3), the amount withheld, deducted, returned or given is a debt owing to the employee and is enforceable under this Act as if it were wages owing to the employee. 


\section{Commencement}

2. This Act comes into force on the day it receives Royal Assent.

Commencement

Short title

3. The short title of this Act is the Protecting Employees' Tips Act, 2013. 


\section{Appendix C}

\section{Telephone/In Person Script:}

Intro: I am looking for volunteers to be interviewed for my Master's thesis research. My study looks at employment standards in restaurants and will use interviews to do this. Are you interested in being interviewed for this project?

$$
\begin{aligned}
& \text { Yes = Continue } . \\
& \text { No = Thank you for your time } .
\end{aligned}
$$

Q1: Have you worked in restaurants/bars in Ontario within the last five years?

$$
\text { Yes }=\text { Continue }
$$

No $=$ Unfortunately you are not eligible for this research study. Thanks again for your interest!

\section{Q2: Are you a woman?}

Yes $=$ Continue

No $=$ Unfortunately you are not eligible for this research study. Thanks again for your interest!

Q3: Are you available for a maximum of two hours to be interviewed at some point between January 1, 2014 and May 31, 2014?

$$
\text { Yes }=\text { Continue }
$$

No $=$ Unfortunately you are not eligible for this research study. Thanks again for your interest! 
Q4: I need to provide an informed consent form for you to sign which will outline the details of this process. Would you be available to meet in the near future to go over this information.

Yes $=$ Schedule a time .

No $=$ Unfortunately you are not eligible for this research study. Thanks again for your interest! 


\section{Appendix D}

\section{Interview Questions}

1. How many restaurants have you been employed for?

2. What style of restaurant(s) have you been employed for? (i.e. pub-style, fine dining, sports bar, family oriented)

3. Can you recall the ratio of men to women serving in each of the restaurants you have worked for?

4. Can you recall the ratio of men to women in managerial positions in each of the restaurants you have worked for?

5. Do you believe that gender was a consideration in the hiring process of any restaurant you have been employed for?

6. Explain the scheduling process in the restaurant(s) you have worked for.

7. Have you ever worked as a full-time employee in a restaurant? If yes:

a) Did you receive benefits?

b) How long did you occupy this full-time position?

c) Were you paid above the serving minimum wage?

8. Explain the allocation of tables to servers in the restaurant(s) you have been employed for.

9. Explain the "tip-out" process in the restaurant(s) you have worked for.

10. Do you believe that tips are equitably shared?

11. Outside of customer service, what factors are known to increase or decrease tips earned?

12. Who has control over these factors and how is this control exercised?

13. Do you believe that tips are reliable?

14. Do you feel like your tips are protected?

15. Describe a situation you have experienced when your tips were determined by factors outside of your control (not including customer service relations). 


\section{Bibliography}

Burnette, J. (2008) Gender, Work and Wages in Industrial Revolution Britain. Cambridge: Cambridge University Press.

Bernstein, S. et al. (2005). Precarious Employment and the Law's Flaws: Identifying Regulatory Failure and Securing Effective Protection for Workers. In Vosko, L. Precarious Employment: Understanding Labour Market Insecurity in Canada (203-220). Montreal and Kingston: McGill-Queen's University Press.

Burnette, J. (2008). Gender Work and Wages in Industrial Revolution Britain. Cambridge: Cambridge University Press.

Canadian Labour Code, R.S.C., 1985, c. L-2

Cohen, M. (2013). Neo-Liberal Crisis/Social Reproduction/Gender Implications. U.N.B.L.J., 234, 1-20.

Connell, R. (2005). Masculinities. Berkley: University of California Press.

Connell, R. and Messerschmidt, J. (2005). Hegemonic Masculinity: Rethinking the Concept. Gender and Society, 19(6), 829-859.

Cotterill, P. (1992). Interviewing women: Issues of frienship, vulnerability, and power. Women's Studies International Forum, 15(5-6), 593-606.

Cox, Robert. (1977). Labour and Hegemony. International Organization, 31(3), 385424.

Creighton, H. (1982). Tied By Double Apron Strings: Female Work Culture and Organization in a Restaurant. Critical Sociology, 11(3), 59-64.

Employment Standards Act, 2000, S.O. (2000, c. 41)

Employment Standards Act: O. Reg. 285/01: Exemptions, Special Rules and Establishment of Minimum Wage. (2000, c. 41)

Finck, H. (1920). Employments Unsuitable for Women. In Bullock, E. Selected articles on the employment of women (76-78). New York: The H.G. Wilson Company.

Fudge, J and Vosko, L. (2001). Gender, Segmentation and the Standard Employment Relationship. Canadian Labour Law, Legislation and Policy, 22(2), 271-310.

Gilbert, Guerrier and Guy. (1998). Sexual harassment issues in the hospitality industry. International Journal of Contemporary Hospitality Management, 10(2), 48-53. 
Gramsci, A. (1994). Prison Notebooks. New York: Columbia University Press.

Giuffre and Williams, (1994). Boundary Lines: Labeling Sexual Harassment in Restaurants. Gender and Society, 8(3). 378-401.

Hall, E. (1993). Waitering/Waitressing: Engendering the Work of Table Servers. Gender and Society, 7(3), 329-346.

Hall, E. (1993). Smiling, Deferring, and Flirting: Doing Gender by Giving "Good Service". Work and Occupations, 20(4), 452-471.

Hawkesworth, M. (2006). Feminist Inquiry - From Political Conviction to Methodological Innovation. London: Rutgers University Press.

Hooks, B. (2000). Feminist Theory: From Margin To Center. Cambridge: South End Press.

Hunt, A. (1990). Rights and Social Movements: Counter-Hegemonic Strategies. Journal of Law and Society, 17(3), 309-328.

Johnson, R. (2005). Law and the Leaky Woman: the Saloon, the Liquor Licence, and Narratives of Containment. Continuum, 19(2), 181-199.

Kavanaugh, R. and Woods, H. (1994). Gender Discrimination and Sexual Harassment as Experienced. Cornell Hotel and Restaurant Administration Quarterly, 35(1), 16-21.

Kessler-Harris. (1988) A Woman's Wage: Historical Meanings and Social Conseences. Kentucky: The University Press of Kentucky.

Ledwith, M. (2001). Community Work as Critical Pegagogy: Re-envisioning Freire and Gramsci. Community Development Journal, 36 (3), 171-182.

Lerum, K. (2004). Sexuality, Power, and Camaraderie in Service Work. Gender \& Society, 18 (6), 756-776.

Lin and Namasivayam. (2011). Understanding restaurant tipping systems: a human resources perspective. International Journal of Contemporary Hospitality Management, 23(7), 923-940.

Liu, C. (2008) The perceptions of waiters and customers on restaurant tipping. Journal of Services Marketing, 22(2), 95-103.

Ministry of Labour, "Complying with the Employment Standards Act (ESA): A Workbook for Employers" (January 2012) 
Maynard and Mupandawana. (2009) Tipping behavior in Canadian restaurants.

International Journal of Hospitality Management, vol. 28 (4), 597-603.

Marx, K. (1998). The Communist Manifesto. Toronto: Penguin Group.

Neumark, D., Bank, R., Van Mort, K. (1996). Sex Discrimination in Restaurant Hiring: An Audit Study. The Quarterly Journal o Economics. 111(3), 915-941.

Oakley, A. (1981). Interviewing Women: A contradiction in terms. in Helen Roberts (ed.) Doing Feminist Research. London: Routledge.

Packard, J. (2008). 'I'm gonna show you what it's really like out here': the power and limitation of participatory visual methods. Visual Studies, 23(1), 63-77.

Pierson. (1983) Canadian Women and the Second World War in Canadian Historical Association Historical Booklet no. 37. Ottawa: Canadian Historical Association.

Plush, T. (2012) "Fostering Social Change through Participator Video: A Conceptual Framework" in Handbook of Participatory Video, Plymouth: Alta Mira Press

Ontario, Legislative Assembly, Official Reports of Debates (Hansard), $40^{\text {th }}$ Parl, $2^{\text {nd }}$ Sess, No 10 (27 November 2013) at 1210 (Hon Lisa McLeod).

Rasmusson, S. (2011) “We're Real Here”: Hooters Girls, Big Tips, \& Provocative Research Methods. Cultural Studies $\leftrightarrow$ Critical Methodologies, 11(6), 574-585.

Slaughter, J. (2011). Gramsci's place in women's history. Journal of Modern Italian Studies. 16(2), 256-272.

Sangster, J. (2010). Transforming Labour: Women and Work in Post-war Canada. Toronto: University of Toronto Press.

Statistics Canada. (2010) Women in Canada: a Gender-based Statistical Report, Paid Work.

Statistics Canada. (1994) Women in the Labour Force, 1994 Edition

Statistics Canada. (2006) Employment Income Statistics (4) in Constant (2005) Dollars, Work Activity in the Reference Year (3), Occupation - National Occupational Classification for Statistics 2006 (720A) and Sex (3) for the Population 15 Years and Over With Employment Income of Canada, Provinces and Territories, 2000 and 2005, 2006.

The Employment Standards Work Group, "OUT WITH THE OLD, IN WITH THE NEW: an Analysis of the ESA 2000 (Bills 147 and 57)" (October 2001) pp. 1-85 
Thomas, M. (2007). Toyotaism Meets the 60-Hour Work Week: Coercion, Consent, and the Regulation of Working Time. Studies in Political Economy, 80, 105-128.

Thomas, M. (2009). Regulating Flexibility: The Political Economy of Employment Standards. Montreal, Kingston: McGill-Queen's University Press.

United Steel, Paper and Forestry, Rubber, Manufacturing, Energy, Allied Industrial and Service Workers International Union (2005) Submission to the Federal Labour Standards Review with respect to Part III of the Canada Labour Code. 1-13

Von Massow and McAdams. (2012). The Tipping Point: Is there a "Fair Share"? University of Guelph Sustainable Restaurant Project.

Vosko, L. (2006). Precarious Employment: Towards an Improved Understanding of Labour Market Insecurity. In Vosko, L. Precarious Employment: Understanding Labour Market Insecurity in Canada. Montreal and Kingston: McGill-Queen's University Press.

Vosko, L. (2010) Managing the Margins: Gender, Citizenship, and the International Regulation of Precarious Employment. Ney York: Oxford University Press.

Vosko, L. (2001). Temporary Work: The Gendered Rise of a Precarious Employment Relationship Toronto: Toronto University Press.

Waite, L. and Conn. (2012) "Participatory Video Drama: A Feminist Way of Seeing?" in Handbook of Participatory Video, Plymouth: Alta Mira Press

Walsh, Eileen. (2008). Representations of Race and Gender in Mainstream Media Coverage of the 2008 Democratic Primary. Journal of African American Studies, 13(2), 121-130.

Whitehead, S. (1998). Hegemonic Masculinity Revisited. Gender, Work, and Organization, 6(1), 58-62. 